\title{
GLA:D Back: implementation of group- based patient education integrated with exercises to support self-management of back pain - protocol for a hybrid effectiveness-implementation study
}

\author{
Alice Kongsted ${ }^{1,2^{*}}$ (D) Inge Ris ${ }^{2}$, Per Kjaer ${ }^{2,3}$, Werner Vach ${ }^{4,1}$, Lars Mors $\varnothing^{5}$ and Jan Hartvigsen ${ }^{2}$
}

\begin{abstract}
Background: Reassuring patient education and exercise therapy are widely recommended interventions for back pain in clinical guidelines. However, many patients are offered non-guideline endorsed options, and strategies for effective implementation of guideline-based care have not yet been developed. This protocol outlines the evaluation of a strategy for nationwide implementation of standardised patient education and exercise therapy for people with persistent or recurrent back pain in a hybrid implementation-effectiveness design. The strategy and the evaluation were planned using the framework of the Behaviour Change Wheel.
\end{abstract}

Methods: The main activity of the implementation strategy is a two-days course for physiotherapists and chiropractors in delivering patient education and exercise therapy that is aimed at supporting patient self-management. This comes with ready-to-use patient education materials and exercise programs. The clinical intervention is a group-based program consisting of two sessions of patient education and 8 weeks of supervised exercises. The program uses a cognitive-behavioural approach and the aim of the exercise component is to restore the patient's ability and confidence to move freely. The implementation process is evaluated in a dynamic process monitoring the penetration, adoption and fidelity of the clinical intervention. The clinical intervention and potential effect mechanisms will be evaluated at the patient-level using measures of knowledge, skills, beliefs, performance, self-efficacy and success in self-management. The education of clinicians will be evaluated via clinician-level outcomes, including the Pain Attitudes and Beliefs Scale, the Practitioner Confidence Scale, and the Determinants of Implementation Behaviour Questionnaire. Effects at a national level will be investigated via data from national registries of health care utilisation and sick-leave.

Discussion: This implementation-effectiveness study is designed to evaluate the process of implementing an evidence-based intervention for back pain. It will inform the development of strategies for implementing evidencebased care for musculoskeletal pain conditions, it will enhance the understanding of mechanisms for developing patient self-management skills, and it will demonstrate the outcomes that are achievable in everyday clinical practice.

Trial registration: ClinicalTrials.gov NCT03570463. Registered 27 June 2018.

Keywords: Back pain, Exercise therapy, Health plan implementation, Patient education, Primary health care

\footnotetext{
* Correspondence: a.kongsted@nikkb.dk

${ }^{1}$ The Nordic Institute of Chiropractic and Clinical Biomechanics, Campusvej

55, 5230 Odense M, Denmark

${ }^{2}$ Department of Sports Science and Clinical Biomechanics, University of

Southern Denmark, Odense, Denmark

Full list of author information is available at the end of the article
}

(c) The Author(s). 2019 Open Access This article is distributed under the terms of the Creative Commons Attribution 4.0 International License (http://creativecommons.org/licenses/by/4.0/), which permits unrestricted use, distribution, and reproduction in any medium, provided you give appropriate credit to the original author(s) and the source, provide a link to the Creative Commons license, and indicate if changes were made. The Creative Commons Public Domain Dedication waiver (http://creativecommons.org/publicdomain/zero/1.0/) applies to the data made available in this article, unless otherwise stated. 


\section{Background}

Back pain is a very common symptom in populations everywhere and is responsible for more years lived with disability worldwide than any other condition $[1,2]$. The societal, health care, and economic burden associated with back pain is high and comparable to those of other prevalent, high-cost conditions such as cardiovascular disease, cancer, mental health, and autoimmune diseases [3].

Clinical guidelines for the treatment of back pain consistently recommend educating patients about back pain and its natural courses, as well as providing advice about remaining active and at work $[4,5]$. In addition, they endorse supervised exercise therapy, manual therapy alone or in combination with exercises, and acupuncture, while discouraging the referral of patients to imaging and the administration of opioids, and reserving surgery for the few with very specific indications [4-6]. Guideline recommendations are, however, often not implemented because implementation of new procedures in clinical practice is challenging [7-9], guidelines are developed without any tools for implementation [10], and effective strategies for implementation have not yet been identified [11, 12]. In addition, reliance on clinical experience, perception of clinical guidelines as subjugating clinical judgment, and a limited knowledge of guideline content, are barriers to clinicians changing their behaviours [13]. Thus, care for back pain patients remains fragmented and ineffective [14, 15]. Moreover, implementation strategies in the field of back pain have generally not been developed and evaluated within a theoretical framework [11-13, 16].

In effectiveness trials, clinicians courses lasting 2 to 9 days in delivering physical and cognitive interventions translated into improved outcomes for people with back pain $[17,18]$. Also, a hybrid design study on the implementation of stratified care for back pain demonstrated altered referral behaviours by family physicians and modestly improved patient outcomes with treatment delivered by 15 community-based physiotherapists trained in a course and receiving a mentoring programme [19].

One challenge in back pain treatment is that effect mechanisms of recommended interventions are poorly understood and mostly not supported by empirical evidence. Self-efficacy, pain distress and fear are involved in the transition from acute to persistent and disabling back pain [20], and pain catastrophising and perceived pain control appear to partly mediate the effects of both physical and cognitive interventions [21-23]. However, there is a need to better understand effect mechanisms if we want to identify the effective aspects of interventions and better understand why seemingly similar patients respond differently to similar treatment. In addition, it is important to note that treatment effects are reliant of the context in which care is delivered, and treatment choices for individual patients are determined by a range of factors including previous experience, expectations and patient-clinician interactions [24-27]. Therefor investigations in a real-life context is needed to understand benefits of care, individual variability in treatment response, and underlying mechanisms.

When effect mechanisms are unknown and transferability from clinical trials to practice is uncertain, the evaluation of implementing interventions in clinical practice should involve both evaluating the process of implementation as well as patient outcomes [28]. Curran et al. described studies that at the same time evaluate implementation and effectiveness at the patient-level as effectiveness-implementation hybrid designs: Type 1 hybrids focusing on effects of a clinical intervention, Type 2 with dual testing of the implementation strategy and the clinical intervention, and Type 3 that tests the implementation strategy while observing outcomes of the clinical intervention [29]. This has been suggested as a way to accelerate the translation of research findings into practice as compared with the traditional phases of up-scaling research from efficacy trials [28].

In summary, there is evidence that implementation interventions can change healthcare practitioner behaviours and potentially improve patient outcomes [12]. However, we could not find examples of studies documenting outcomes of nationwide implementation of back pain treatments, nor did we find investigations of whether implementation of recommended care can be achieved by making training generally available to back pain clinicians. Finally, there is a need for understanding how back pain treatments work in a general clinical context.

This protocol describes a hybrid effectiveness-implementation type 3 study [29], which will evaluate the national implementation of a standardised care package for people with back pain, GLA:D Back [30]. GLA:D Back will expand an existing program 'Good Life with OsteoArthritis in Denmark' for patients with knee or hip pain to people with back pain [31]. It aims to improve self-management in people with persistent or recurrent back pain by translating recommendations from clinical guidelines into an intervention that consists of groupbased patient education and supervised exercises with data from patients enrolled in GLA:D Back included in a clinical registry that monitors patient profiles and outcomes. The main activity for implementation consists of a course for physiotherapists and chiropractors in delivering GLA:D Back and access to materials needed for the delivery of this intervention. The mode of implementation was tested in a feasibility study with physiotherapists and chiropractors from nine clinics that all managed to implement the intervention following the course. These pilot clinics enrolled 89 patients in the 
GLA:D Back programme and 161 in two comparison groups as part of the feasibility testing. A mixed methods evaluation showed good promise for adoption of the clinical intervention after clinicians' course participation, for the data collection and for positive outcomes with the GLA:D Back intervention [32].

This protocol describes the methods for evaluation of the initial roll-out of GLA:D Back. This includes evaluating the clinical intervention targeted at patients, the educational intervention targeted at clinicians, and the national implementation.

The study objectives for the evaluation of the clinical intervention are:

- To describe changes in patient outcomes after participation in GLA:D Back and evaluate if these are of a magnitude comparable with those observed in RCTs on combined patient education and exercise interventions for persistent and recurrent back pain,

- To determine to what extent patterns of health care utilisation and sick leave change in individuals from one year before participation in GLA:D Back to one year after,

- To determine if patient outcomes are associated with clinicians' treatment orientation and confidence,

- To identify subgroups of patients who do not benefit sufficiently from the GLA:D Back clinical intervention, and

- To investigate potential mechanisms of change in patient outcomes.

With respect to within subject changes we hypothesise that the clinical intervention is as effective as previously observed changes in RCTs on similar interventions.

The study objectives for the evaluation of the clinician educational intervention are:

- To monitor outcomes of learning activities and adapt the delivery of the clinician course accordingly,

- To determine if there is a change in treatment orientation from a biomedical to a more behavioural orientation and an increase in clinicians' confidence in managing people with back pain following the GLA:D Back course,

- To identify clinician factors related to treatment orientation and confidence in managing back pain, and

- To determine if treatment orientation and clinicians' confidence are associated with clinical behaviours.

We hypothesize that the educational intervention is effective in preparing the clinicians to deliver the clinical intervention as intended.
The study objectives for the evaluation of the national implementation are:

- To monitor the promotion of GLA:D Back courses and adapt the promotion strategy when prespecified criteria are not met,

- To describe the penetration, adoption, and fidelity of GLA:D Back including the degree of uniformity across clinicians, clinics, and regions,

- To identify individual and organisational determinants of adoption and fidelity, and

- To evaluate the effects of the implementation on referrals to imaging and secondary care for back pain, opioid prescription, and sick leave rates at the national level.

We hypothesize that in the long run the implementation will imply reductions in referrals to imaging and secondary care and in opioid prescriptions for back pain at the national level.

\section{Methods}

This protocol is presented in accordance with the Standards for Reporting Implementation Studies (StaRI) Statement [33], and the educational intervention for clinicians in agreement with the Guideline for Reporting Evidence-based practice Educational interventions and Teaching (GREET) [34]. The study was registered in Clinicaltrials.gov May 2018 (ID: DPA 2015-57-0008 SDU 17/30591).

\section{Theoretical framework}

We used The Behaviour Change Wheel as a theoretical framework for aligning the objectives, strategies and evaluation of implementation. It was developed as a framework for characterising interventions and policies intended to change behaviour [35]. It is based on elements from 19 theoretical frameworks of behaviour change and incorporates domains from the Theoretical Domains Framework. The Behavior Change Wheel links types of interventions to mechanisms of behaviour change centred on three core elements: 'Capability', 'Opportunity', and 'Motivation' the (the COM-B model), and provides a framework for considering both organisational and individual levels of implementation (Fig. 1).

\section{Context}

Denmark is a European country with around 5.7 million inhabitants. It spends approximately $10 \%$ of its gross domestic product on healthcare, $10-16 \%$ of which is spent on primary care [36]. Danish primary care is administered by five regions and 98 municipalities. The regions are responsible for most of the primary care services including general practitioners (GPs), physiotherapists, 


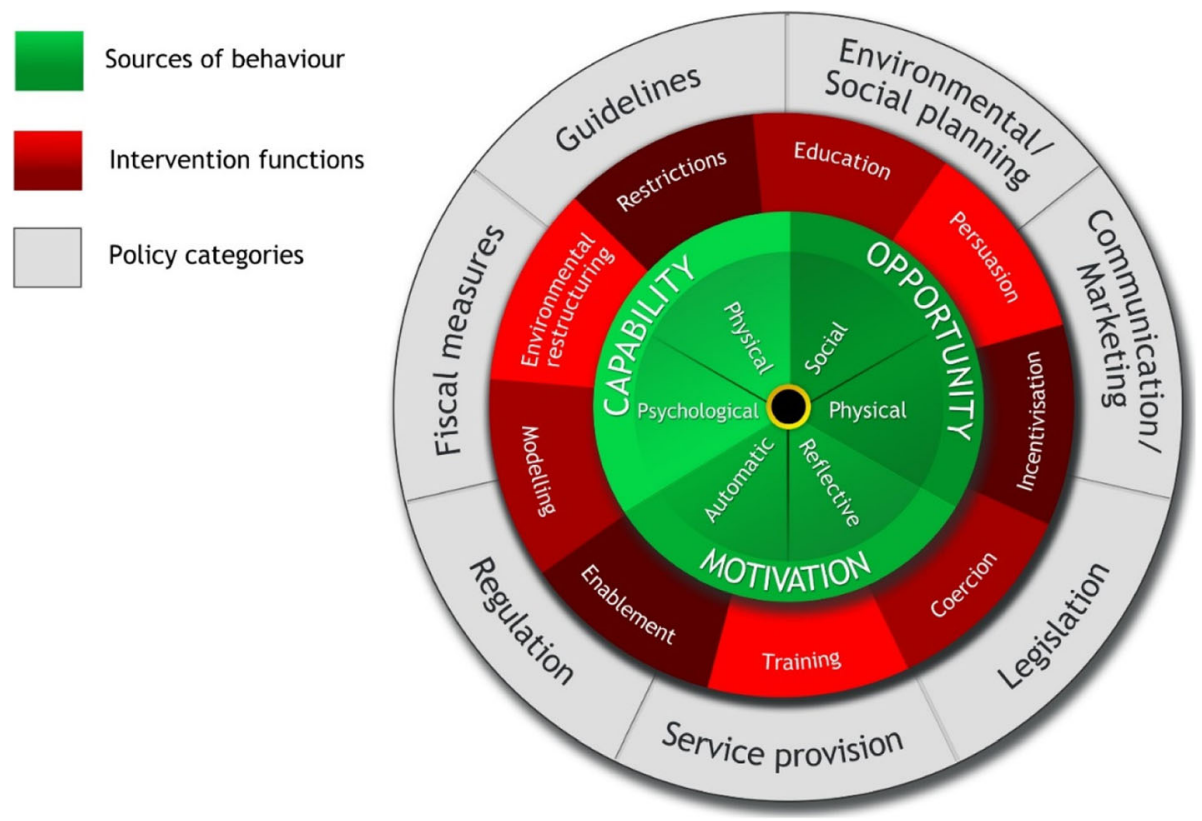

Fig. 1 The Behaviour Change Wheel. Susan Michie et al. Implementation Science 2011 6:42 [35]

and chiropractors whereas the municipalities are responsible for rehabilitation.

GPs, physiotherapists and chiropractors in primary care are self-employed and most have a contract with the state-funded universal health insurance that is negotiated collectively by their professional organisations. In 2017, approximately 4100 GPs, 2850 physiotherapists and 410 chiropractors were covered by these agreements [37]. Visits to GPs are fully reimbursed with no outof-pocket expenses incurred by the patient, whereas between 60 and $80 \%$ of the fee for physiotherapy and chiropractor services are paid for by the patient directly or through a private insurance company. Costs associated with physiotherapy are reimbursed by the regions only if patients are referred by a GP, whereas reimbursement for chiropractic costs is independent of referral. Both chiropractors and physiotherapists can offer services outside of these contracts, but in these situations there is no reimbursement or negotiated prices. Approximately $25 \%$ of chiropractic clinics have at least one physiotherapist employed as a member of the staff [38].

In addition to the universal health care coverage, approximately 1.9 million Danes currently have private health insurance fully or partially covering out-of-pocket expenses for services from physiotherapists, chiropractors, psychologists and other providers.

GLA:D for patients with knee and hip pain was established as a non-profit initiative by the University of Southern Denmark (SDU) in 2013 [31]. The GLA:D trademark is registered by SDU and is reserved for initiatives that train clinicians in delivering guideline-supported interventions for musculoskeletal disorders with outcomes recorded and monitored in a registry approved by SDU. After 5 years, more than 1000 physiotherapists from primary care and municipalities have participated in a GLA:D course and 32,600 patients have been recorded in the GLA:D registry, up until May 2018. As such, GLA:D is the only Danish example of a well-described clinical intervention for musculoskeletal conditions that is widely available and for which there is a systematic registration of patient-reported and clinical outcomes. Since 2016, one region has provided additional reimbursements for GLA:D knee and hip, and in that region it is now a requirement that patients have participated in a course of structured, supervised exercises prior to being seen by a surgeon in a public hospital. To date, there has not been any systematic evaluation of the implementation of GLA:D knee and hip.

\section{Interventions}

\section{The GLA:D Back clinical intervention}

This clinical intervention is intended for people with persistent or recurrent low back pain (LBP) and in need of improved self-management. The content and intervention mapping are presented in detail elsewhere [30]. Briefly, GLA:D Back consists of an individual session of clinical testing and goal-setting at the beginning and end of the program, two one-hour group sessions of patient education, and 8 weeks of twice-weekly one-hour supervised exercises sessions (Fig. 2).

The overall aim of GLA:D Back is to improve the participant's ability to self-manage and the content is based 


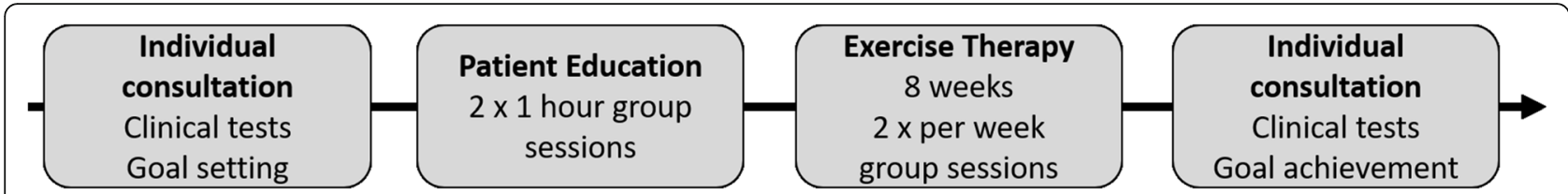

Fig. 2 Outline of the clinical intervention

on a cognitive behavioural approach aimed at supporting pain self-efficacy. Theoretically, the proposed effect mechanisms are that the knowledge and skills achieved during participation in the program translate into changed believes and performance, which in turn will improve self-efficacy, decrease disability, increase quality of life, and ultimately reduce health care utilisation and sick leave (Fig. 3).

Clinicians can adapt GLA:D Back to their particular setting and to the needs of individual patients, however, the following core parts cannot be altered: 1) an individual session at the beginning and the end of the program with goal-setting and physical tests, 2) $2 \mathrm{~h}$ of patient education and 16 sessions of supervised exercises over 8 to 10 weeks, 3) key messages stating that pain is not a sign of danger, 4) an explanation of back pain using a behavioural model of (im) balance between demands and capacity rather than emphasising tissue damage (Fig. 4), 5) guidance for patients in exploring movement rather than being taught to perform exercises in one 'correct' manner, and 6) entry of data into the clinical registry. Refinements of the content of the patient education or exercise program will be made continuously by the research group without violating these principles.

\section{The clinician educational intervention}

Clinicians are trained in a two-day course ( $7 \mathrm{~h}$ each day) delivered by the developers of the program (AK, IR, PK, $\mathrm{JH}$ ) and by employed expert clinicians. The course program can be seen in Additional file 1.

The primary aim of the course is to motivate clinicians to adapt a behavioural rather than a biomedical/structural treatment orientation and to provide tools that support the implementation of the GLA:D Back program. The GLA:D Back course was developed using the COM-B model in order to supports clinicians' behaviour change by improving their capability, motivation and opportunity to change. The learning goals are pursued by using different educational elements including education

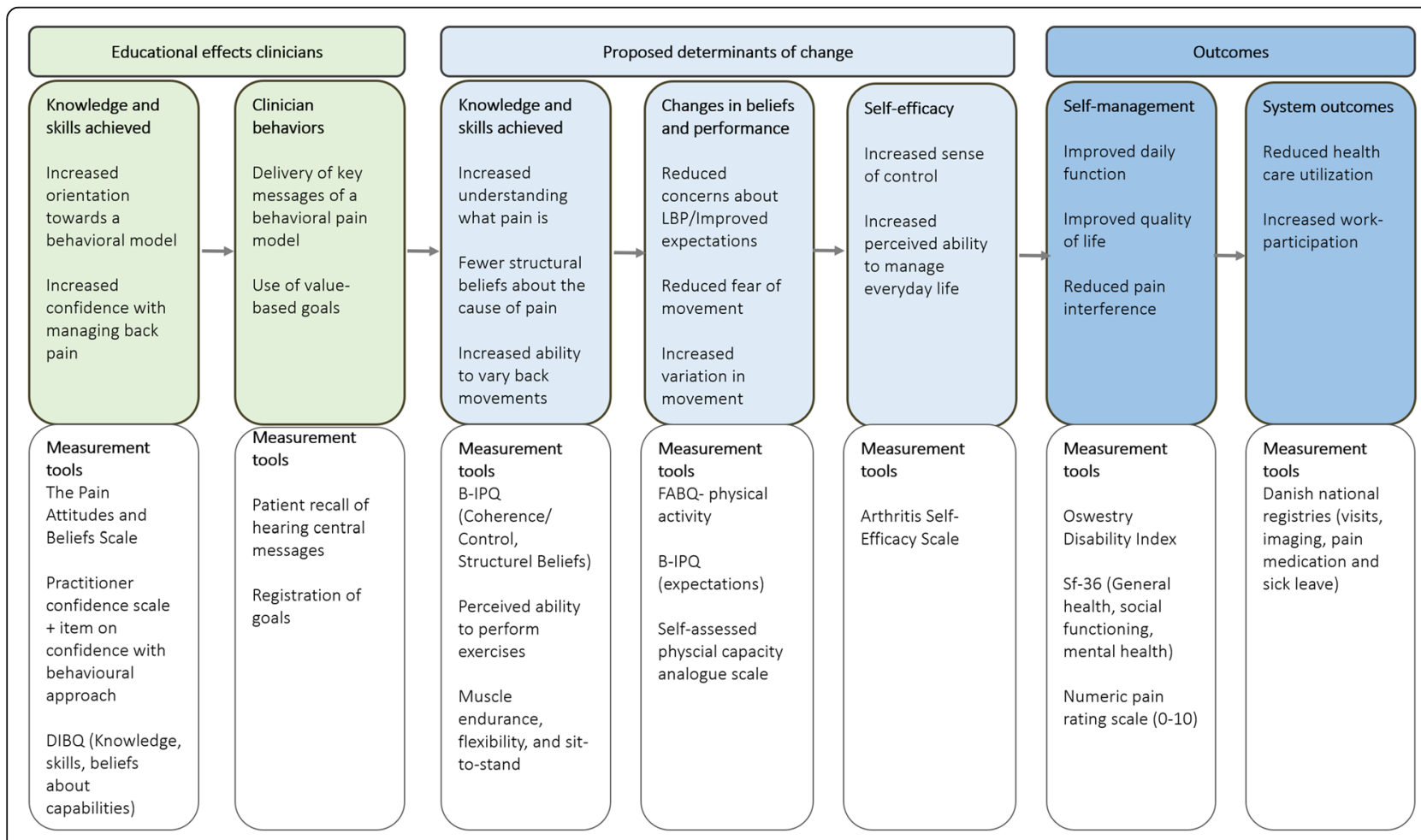

Fig. 3 The theoretical model of change at the clinician level and the patient-level 


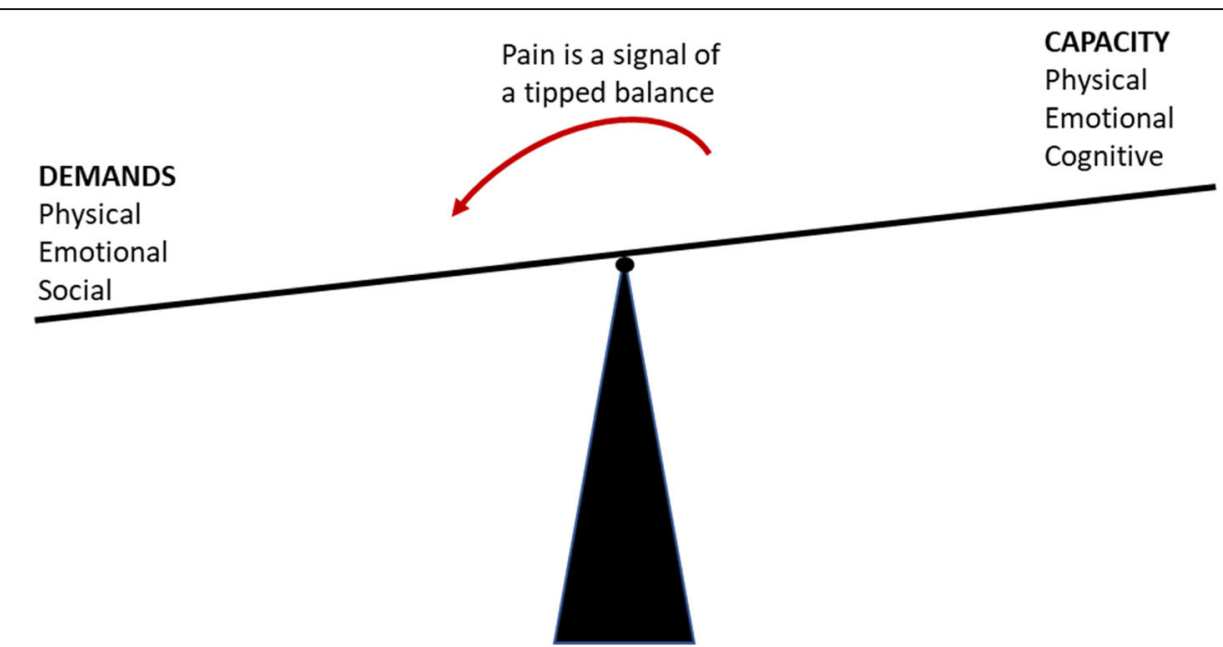

Fig. 4 Illustration from the patient education explaining that pain is a result of your demands (physical, emotional and social) exceeding your capacity (physical, emotional, and cognitive)

through lecturing, persuasion and modelling by examples, in addition to skills training (Table 1).

First, participants acquire an understanding of the content of the clinical intervention and the arguments for standardised care. They are presented with an overview of current evidence about the burden of LBP, evidence supporting persistent LBP as a non-injury pain condition, a brief introduction to pain modulation and the cognitive behavioural model [39], and a summary of the evidence base for GLA:D Back. Clinicians are informed that GLA:D Back was developed for people with persistent or recurrent non-specific LBP who have a need for improved self-management, and the decision as to whether or not a patient enters the program is left up to their clinical judgement and the patient's motivation.

Second, the main body of the course is aimed at developing participants' ability to deliver the GLA:D Back clinical intervention as a way of addressing pain cognitions and behaviours by introducing all elements of the clinical intervention: goal-setting, clinical tests, patient education and supervised exercises. Goal-setting is introduced by presenting the SMART-model (Specific, Measurable, Acceptable, Realistic, and Time bound goals) [40]. Role plays to practice the use of explanatory models and skills training are used to become familiar with pain education, physical tests and exercises. Using some of the slides from the patient education material, participants work in groups taking turns to deliver key messages from the pain education to each other as they would in a real patient session, evaluated using peer feedback. The clinical tests and exercises are introduced in a practical session where tests are carried out on a colleague, and exercises are performed by the participants while examples of variations are presented. The supervision of exercises is practised in a session based on video cases and centred on the messages (spoken and unspoken) that can be delivered while supervising patients in the clinic. Key messages from the patient education should be reinforced during the instruction of exercises, for example, when explaining to patients how to cope with pain provocation during exercises rather than withdrawing from the activity. Finally, participants are introduced to the clinical registry used for data entry. At the end of Day 2, clinicians plan how and when to start GLA:D Back in their clinics. They are encouraged to pursue implementation by referring to the success of the GLA:D Knee/Hip model and the experience with GLA:D Back from pilot testing, as well as by emphasising the importance of physiotherapists and chiropractors taking on the role of ensuring access to evidence-based care for back pain.

Courses may be refined during the process of implementation, however, the core parts that are not subjects to change are: 1) familiarising participants with the key messages of the clinical intervention, 2) the introduction to the clinical registry, and 3) that the clinicians practice the delivery of patient education and the instruction of exercises during the course.

\section{The national implementation}

The national implementation will be driven by clinicians who have attended the course and are trained in GLA:D Back. Therefore, the first step was to generate awareness of the development of GLA:D Back in professional journals, at seminars and meetings, and by mentioning the new initiative at the GLA:D Knee/Hip courses. Then, in August 2017, nine clinics (31 clinicians) participated in piloting the GLA:D Back program and took their own initiatives to promote their participation via websites, social media and contact with GPs. 
Table 1 Learning goals and learning activities of the clinician course based on the COM-B model

\begin{tabular}{|c|c|c|c|}
\hline $\begin{array}{l}\text { COM-B } \\
\text { TDF domains }\end{array}$ & Learning goals & Learning Activity (Interventions) & Evaluation tools \\
\hline \multicolumn{4}{|l|}{ Motivation } \\
\hline $\begin{array}{l}\text { Social/professional } \\
\text { role and identity }\end{array}$ & $\begin{array}{l}\text { Clinicians perceive their role in } \\
\text { ensuring high-quality care as } \\
\text { important }\end{array}$ & $\begin{array}{l}\text { A 'state-of-the-art' lecture including an } \\
\text { overview of the evidence on the burden of } \\
\text { back pain, the prognosis of back pain and the } \\
\text { call for non-pharmacological, non-surgical } \\
\text { interventions in clinical guidelines (Ed) }\end{array}$ & DIBQ (Social influences) \\
\hline $\begin{array}{l}\text { Beliefs about } \\
\text { capabilities }\end{array}$ & $\begin{array}{l}\text { Clinicians feel confident that they are } \\
\text { able to deliver GLA:D Back }\end{array}$ & $\begin{array}{l}\text { Reinforcement that most of the skills needed } \\
\text { are pre-exiting among educated clinicians (Ed) } \\
\text { Group exercises focused on practising delivery } \\
\text { of key messages of the patient education. } \\
\text { Participants take turns in playing the roles of } \\
\text { the teaching clinician and mentor. A scoring } \\
\text { guide (rubric) is used to facilitate feed-back } \\
\text { (En, } T \text { ) } \\
\text { Clinicians receive the patient education } \\
\text { content as a slideshow with manuscript, } \\
\text { exercise programs and handouts containing } \\
\text { examples of language to be used in } \\
\text { delivering key messages (En) }\end{array}$ & $\begin{array}{l}\text { Practitioner Confidence Scale } \\
\text { DIBQ (Skills, Knowledge, Beliefs } \\
\text { of capabilities) }\end{array}$ \\
\hline
\end{tabular}
Clinicians believe that GLA:D Back
will add value

Beliefs about consequences

Intentions

Reinforcement

Emotion

Capability

Knowledge
Clinicians agree with a need for standardised evidence-based back pain care

Clinicians have positive attitudes towards a behavioural model for back pain treatment

Clinicians intend to offer GLA:D Back in their clinics

Clinicians are aware that GLA:D for hip and knee has been well received by physiotherapists, patients, general practitioners and politicians

Clinicians appreciate the value of being a GLA:D Back instructor

Clinicians know current recommendations for treatment of back pain

Clinicians know the GLA:D Back approach to support patients' self-management
A recording of a patient interview providing a patient's views on what was gained from taking part in GLA:D Back (P)

Posters placed at the course venue with quotes from clinicians and patients who have experienced GLA:D Back (P)

Presentation of facts about the adoption of GLA:D knee and hip and the achieved political agreements for integrating GLA:D in disease management programs with reduced out-ofpocket expenses (Ed, I, M)

Lecture about 'state-of-the-art', pain

mechanisms, the evidence-base for GLA:D

Back and the hypothesised mechanisms of action (Ed)

Presentation of patient outcomes and

statements from clinicians about experiences with GLA:D Back (P, I)

A recording of a patient interview providing a patient's views on what was gained from taking part in GLA:D Back (P)

Facilitated group discussion about practical organisation with examples of solutions from test-sites (M)

Participants documenting a plan on when, where, who, and how to initiate the GLA:D Back-program in their clinic $(P, E n)$

Presentation of facts about the spread of GLA:D knee and hip, the patient outcomes, and the achieved political agreements for integrating GLA:D in disease management programs with reduced out-of-pocket expenses (Ed, I, M)

A recording of a patient interview providing a patient's views on what was gained from taking part in GLA:D Back (I)

A 'state-of-the-art' lecture including an overview of the content of clinical guidelines on treatment $(\mathrm{Ed})$

A lecture on the patient education that links the content of GLAD Back to self-efficacy (Ed) A lecture about value-based goals,
DIBQ (Beliefs about consequences)

DIBQ (Beliefs about consequences, Patients, Innovation)

The Pain Attitudes and Beliefs Scale

DIBQ (Behavioural regulation, Intentions)

Intended time point for starting the first GLA:D Back-group

Not measured

Not measured

DIBQ: Knowledge 
Table 1 Learning goals and learning activities of the clinician course based on the COM-B model (Continued)

\begin{tabular}{|c|c|c|c|}
\hline $\begin{array}{l}\text { COM-B } \\
\text { TDF domains }\end{array}$ & Learning goals & Learning Activity (Interventions) & Evaluation tools \\
\hline & $\begin{array}{l}\text { Clinicians know why SMART } \\
\text { value-based goals are used }\end{array}$ & $\begin{array}{l}\text { demonstration of web-tool for goal registration, } \\
\text { examples from the pilot }(E d, T, I)\end{array}$ & \\
\hline Skills & $\begin{array}{l}\text { Clinicians can identify relevant } \\
\text { patients for the program } \\
\text { Clinicians can deliver the key } \\
\text { messages of the patient education } \\
\text { Clinicians can support patients in } \\
\text { identifying goals } \\
\text { Clinicians know how to perform the } \\
\text { exercises in the program } \\
\text { Clinicians can apply knowledge of } \\
\text { the non-structural pain model in the } \\
\text { supervision of exercises }\end{array}$ & $\begin{array}{l}\text { Definition of the target group for the clinical } \\
\text { intervention (Ed) } \\
\text { Provision of examples of explaining back pain } \\
\text { using the educational material }(T) \\
\text { Provision of examples of questioning } \\
\text { technique for identifying goals }(T) \\
\text { Instructions on how to perform Texercises in } \\
\text { the program ( }(T) \\
\text { Group exercises focused on practising the } \\
\text { delivery of central messages of the patient } \\
\text { education. Participants take turns in playing }\end{array}$ & $\begin{array}{l}\text { Enrolled patients report long- } \\
\text { lasting or recurrent LBP and } \\
\text { have similar profiles across } \\
\text { clinicians } \\
\text { Delivery of central messages } \\
\text { (patient reported) } \\
\text { Use of individual goals } \\
\text { registration in the registry } \\
\text { DIBQ: Skills, beliefs about } \\
\text { capabilities } \\
\text { Clinicians use the register }\end{array}$ \\
\hline
\end{tabular}

Behavioural regulation (action planning, breaking habits)
Clinicians know how to get started with GLA:D Back

\section{Opportunity}

Environmental context and resources

\author{
Clinicians know that the programme \\ does not require high-tech \\ equipment
}

Clinicians see how the programme can fit into existing routines and payment structures the roles of the clinician teaching and the

patients with diverse issues and worries (En) Exercise based on video cases to practice how messages from the patient education are used in the instruction of exercises. A scoring guide (rubric) is used to facilitate the evaluation of cases (En)

A lecture on using the digital platform to enter data (Ed)

Clinicians documenting a plan for when, where and how to start their first GLA:D Backgroup and discuss their plan in groups (En) A lecture on using the digital platform to enter data (Ed)

Following the course, access to educational materials, exercise programs and instructions for clinical tests are available online. Clinicians have access to the technical support and to the research team for guidance when questions arise (En)

Emphasising the use of low-tech equipment while delivering the GLA:D programme throughout the course and demonstrating this when teaching the exercises (E, En)

Workshop where clinicians share experiences with implementing back programs and are able to ask questions of expert clinician

\section{Patients are enrolled in and complete the GLAD programme}

\footnotetext{
An overview of the learning goals, course activities and clinician-level outcomes in GLA:D Back intended to address elements that, within the Theory of Planned Behaviour, affect clinicians' intentions to change and their actual change in behaviour. The interventions of Education, Training, Enablement and Incentivisation are defined as part of the Behavioural Change Wheel

Ed Education - Increasing knowledge and understanding, P Persuasion - Inducing feelings to stimulate action, $T$ Training - Communicating skills, En Enablement Reducing barriers to increase capability, I Incentivisation - Creating expectation of reward, M Modelling - Exemplifying to aspire or imitate, $E$ Environmental restructuring - changing context (physical/social), DIBQ Determinants of Implementation Behaviour Questionnaire
}

In February 2018, when course registration opened for all interested chiropractors and physiotherapists, the Danish Physiotherapy Association and the Danish Chiropractors' Associations and some physiotherapy special interest groups were asked to advertise the program to their members. The GLA:D Back website, and an invitation to register, were also promoted by the research team on Facebook, LinkedIn and Twitter and to clinicians who use the GLA:D register for knee/hip patients when they logged on to the registry (Table 2). Course participation is at a cost of approximately $€ 550$ (2018).
Clinicians who participate in the course and decide to deliver GLA:D Back at their clinic are listed as certified clinicians on the GLA:D Back website (http://gladryg.s$\mathrm{du} . \mathrm{dk} /$ ). Because GLA:D is a registered trademark, only clinicians trained at SDU can use the brand, and sustained certification comes with the requirement to enter all appropriate patient information into the clinical registry. Updates and re-certification are planned for the future.

To support the implementation after the course, clinicians are given access to detailed patient educational materials, exercise programs, and written suggestions of language that can be used in the supervision of exercises 
Table 2 Promotion activities and pre-defined minimum standards for the planned activities and for reach

\begin{tabular}{|c|c|c|}
\hline Planned promotion activity & Interval & Minimum standard \\
\hline Article on the Danish Physiotherapists' web site & Completed 2017 & NA \\
\hline Poster presentation Danish Chiropractors' Association meeting & Completed 2017 & NA \\
\hline $\begin{array}{l}\text { Series of three letters on standardised care in a magazine for } \\
\text { members of Danish Chiropractors' Association }\end{array}$ & Completed 2017 & NA \\
\hline $\begin{array}{l}\text { The Danish Chiropractic Association (DCA) informs members } \\
\text { that course registration is open }\end{array}$ & Once before registration opens & $\begin{array}{l}\text { One newsletter e-mailed to } \\
\text { members of the DCA } \\
\text { News posted on the DCA's } \\
\text { website }\end{array}$ \\
\hline $\begin{array}{l}\text { The Danish Physiotherapy Association informs members that } \\
\text { course registration is open }\end{array}$ & Once before registration opens & $\begin{array}{l}\text { One newsletter e-mailed to } \\
\text { members of the Association } \\
\text { News posted on the Association's } \\
\text { website }\end{array}$ \\
\hline $\begin{array}{l}\text { Information about the GLA:D Back courses at websites of } \\
\text { physiotherapy special interest groups } \\
\text { - Musculoskeletal physiotherapy } \\
\text { - Sports physiotherapy } \\
\text { - Physiotherapists in private practice } \\
\text { - Physiotherapists without a contract with the board of wages } \\
\text { and fees }\end{array}$ & Once before first course registration closes & $\begin{array}{l}\text { One of the listed groups posts } \\
\text { the information }\end{array}$ \\
\hline $\begin{array}{l}\text { Direct e-mail to the five regions' private practice consultants } \\
\text { from chiropractic, physiotherapy and general practice }\end{array}$ & $\begin{array}{l}\text { Once when information about opening } \\
\text { the registration is known }\end{array}$ & $\begin{array}{l}\text { Mail send before registration } \\
\text { opens }\end{array}$ \\
\hline $\begin{array}{l}\text { Information to clinicians who deliver GLA:D for knee/hip } \\
\text { patients on the front page of the knee/hip clinical registry }\end{array}$ & When registration is open & $\begin{array}{l}\text { Information posted one time } \\
\text { before opening }\end{array}$ \\
\hline $\begin{array}{l}\text { Promotion of GLA:D Back via social media (Twitter, Facebook, } \\
\text { ResearchGate, Linkedln) }\end{array}$ & $\begin{array}{l}\text { When GLA:D Back related external activities } \\
\text { (courses, talks) and publications occur }\end{array}$ & $\begin{array}{l}\text { One posting per month during } \\
2018\end{array}$ \\
\hline $\begin{array}{l}\text { Workshop at the yearly seminar for general practitioners } \\
\text { "Lægedage" }\end{array}$ & November 2018 + November 2019 & One workshop accepted \\
\hline $\begin{array}{l}\text { Clinicians who participated in the course and wanted to } \\
\text { deliver the intervention listed at the GLA:D Back website }\end{array}$ & After courses are conducted for a region & $\begin{array}{l}\text { Updated within } 2 \text { weeks of the } \\
\text { last course for a region }\end{array}$ \\
\hline Target & Group definition & Minimum standard \\
\hline \multirow[t]{6}{*}{ Number of clinicians educated in 2018} & The Capital Region of Denmark & 60 \\
\hline & Region Zealand & 60 \\
\hline & Region of Southern Denmark & 60 \\
\hline & Central Denmark Region & 60 \\
\hline & The North Denmark Region & 60 \\
\hline & Total & 300 \\
\hline \multirow[t]{2}{*}{ Years of clinical experience (min. proportion) } & $0-5$ & $10 \%$ \\
\hline & $>15$ & $10 \%$ \\
\hline Sex & Proportion males & Min 33\% Max 66\% \\
\hline \multirow[t]{4}{*}{ Work place and role (min. proportion) } & Municipality & $5 \%$ \\
\hline & Private clinics & $60 \%$ \\
\hline & Clinic owner & $5 \%$ \\
\hline & Employed clinician & $50 \%$ \\
\hline \multirow[t]{2}{*}{ Profession (minimum proportion) } & Physiotherapist & $70 \%$ \\
\hline & Chiropractor & $10 \%$ \\
\hline
\end{tabular}

after the course. They also are given GLA:D Back logo $\mathrm{t}$-shirts and posters for the clinic with key messages from the patient education and an overview of the exercises [30]. To assist a uniform promotion of the program, clinicians get information leaflets directed at patients and at GPs that can be used with their individual clinic names and logos.

There are no strict patient inclusion criteria, and the decision to enrol a patient in GLA:D Back is at the discretion of the clinician in a dialogue with the patient, 
when clinicians judge that the patient would benefit from improved self-management skills. Patients can be enrolled at the first visit or later depending on whether individual treatment sessions are deemed necessary prior to starting GLA:D Back. When patients begin the program their contact information is entered in the clinical registry, which in turn activates links to patient questionnaires that are sent automatically on the day of registration and again after 3, 6 and 12 months. Clinicians enter results of physical tests and patients' individual goals in the registry before patients start the GLA:D Back intervention and when the program ends. The price and out-of-pocket expenses for the GLA:D Back intervention can vary between clinics and types of insurance.

Consultants for physiotherapy, chiropractic, and family medicine working with primary care in the five administrative regions were invited to an information meeting about GLA:D Back before course registration was opened (January 2018). Family physicians will be informed through professional journals and seminars.

\section{Effectiveness and process evaluations Data collection}

Data sources will include: 1) data obtained from clinicians when they register for a GLA:D Back course, 2) clinician-completed surveys before and directly after the course and after 5-months, 3) observations of patient education and exercise group sessions in selected clinics, 4) patient physical tests at baseline and at the end of treatment, 5) patient-completed surveys at baseline, 3-months, 6-months and 12-months, 6) patient interviews, and 7) information from Danish registries (Fig. 5). Patient and clinician data are collected electronically using the REDCap software (Vanderbilt University) provided and supported by the Odense Patient data Explorative Network (OPEN) [41].

\section{Evaluation of the clinical intervention}

The clinical intervention will be evaluated based on data about the patients who enrol in the GLA:D Back program, i.e. those patients who are registered in the GLA:D Back registry.

Due to the lack of a control group we will compare mean changes in these patients with those observed in the intervention groups of trials that have demonstrated positive effects of patient education and exercise therapy. We will look for trials with little risk of bias that included patient populations comparable with those enrolled in GLA:D Back.

Health care utilisation and sick leave will be investigated using national registry data to compare individual patterns of health care utilisation (primary care visits, hospital visits due to LBP, imaging for LBP, prescriptions for pain medication) and sick leave from 1 year before participation in GLA:D Back to 1 year after participation (Fig. 5).

Clinicians' beliefs about back pain and confidence in managing patients with LBP (described below) and their baseline characteristics will be investigated as potential predictors of patient outcomes. Potential mechanisms of change in patients will be investigated by testing the mediating pathways outlined in the theoretical model (Fig. 3). We will specifically test the extent to which improved illness beliefs, increased perceived ability to perform exercises, and improvements on physical tests may explain a reduction in fear avoidance, improvement in expectations and increased self-assessed physical capacity during the 3 months after inclusion

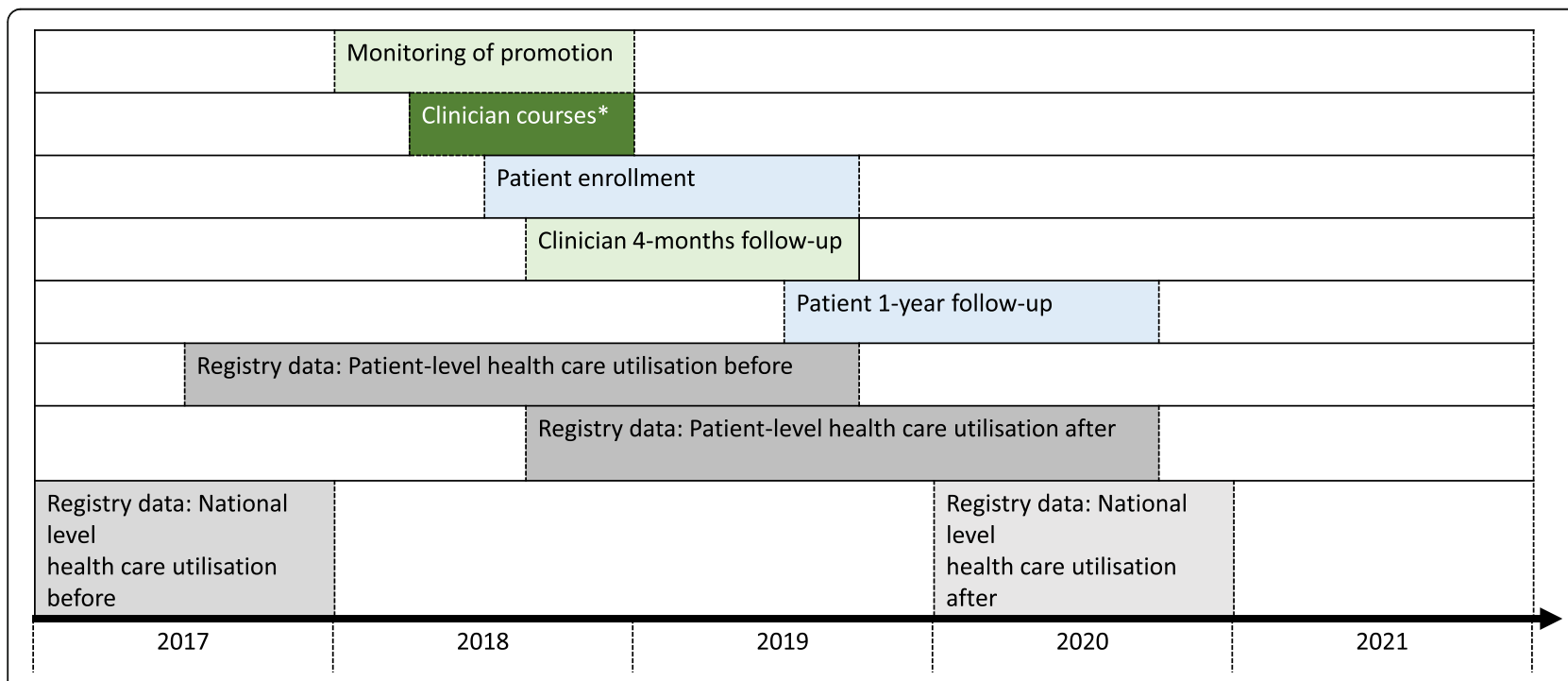

Fig. 5 Study timeline. * Clinician data collected before and after the course 
and during the following 3 months (3- to 6-months follow up). We will then test to what extent reduced fear avoidance beliefs, improved expectations and increased physical capacity during the initial 3 months relate to an increase in self-efficacy during the same period and to improved self-efficacy after 6 and 12 months. Next, we will investigate the relationship between increased self-efficacy and outcomes of selfmanagement success, and whether self-efficacy is a mediator between beliefs and performance and success in self-management. Lastly, we will test to what extent improvements in disability, quality of life and pain after 6 months predict health care utilisation and sick leave after 12 months, to what extent improved self-efficacy influences these outcomes, and if this is fully or partly explained by improvements in self-management.

Patients' perceptions related to developing pain self-efficacy and ability to self-manage will be explored using individual interviews that address back beliefs, perceived ability to manage LBP, and what aspects of the LBP experience need to change during and after participation for patients to consider the intervention beneficial.

\section{Evaluation of the clinician educational intervention}

All clinicians participating in a course will be included in this evaluation. The course content and delivery will be evaluated via observations by an expert in medical education to confirm that the planned learning activities are delivered. Outcomes of learning activities (Table 1) will be compared between courses and any trends in change over time described.

Evaluations of clinician-level outcomes will be investigated in an observational longitudinal design with clinician-reported data collected before the clinician training course, immediately after the course and 5 months later, and with patient-reported information on delivery collected at their three-months follow up. Changes over time in treatment orientation and confidence in managing patients with LBP will be described, and potential relationships between clinician characteristics, treatment orientation and confidence will be determined.

\section{Evaluation of the national implementation}

The implementation process will be evaluated, starting with the promotion of courses for clinicians, the degree of course participation, the adoption and fidelity of the implementation in the clinics, through to the potential impact on health care utilisation at a national level. An evaluation of sustained implementation is not part of this protocol. Elements of the process evaluation are listed in Table 3.

Promotion of courses and pre-defined minimum standards for each element of the promotion strategy will be monitored during the roll-out (Table 2). A research team, not otherwise involved in GLA:D Back, will conduct the monitoring and provides feedback to the GLA:D Back project group at regular intervals, which in turn will determine the actions required when standards are not met. For example, if one region has less than 60 clinicians registered, this will be fed back to the project group with information on any particular clinician groups (e.g. related to professional background or clinical experience) that appears not to have been reached so that actions can then be taken to reach that specific group(s).

The adoption of GLA:D Back will be investigated by measuring the extent to which clinicians who have participated in the GLA:D Back course conduct the program in their clinics. Individual clinician factors and organisational factors will be investigated as determinants of adoption.

Fidelity will be investigated quantitatively by asking about treatment content and recall of key messages via patient questionnaires, and by ensuring that patients' individual goals are registered. The quality of care in terms of delivering the key elements of the intervention will be further explored by video-based observations and from patient interviews that will provide a patient perspective on the content of care.

The profile of patients enrolled in the GLA:D Back programme will be compared between clinics and administrative regions to investigate if clinicians seem to agree on the target group as well as detect if regional politics or planning affects patient selection. Also, the proportion and profile of patients enrolled who do not complete the program will be compared across clinician profiles and regions. Finally, we will ask clinicians about their experience with patients being motivated to enrol in the program and the reasons why patients considered suitable candidates for the program declined participation.

The frequency of referrals to imaging and to secondary care for back pain, opioid prescription and long-term sick leave related to LBP at the national level will be compared between 2016 and 17 before implementation starts and during 2020-21, i.e. commencing one year after all Danish regions have had clinicians educated. Comparisons will be made at the overall population level as well as for populations with a history of LBP identified from sources such as The Danish National Health Survey.

\section{Outcome measures}

Outcomes at the clinician level and patient level will be matched to the theoretical model of change in Fig. 3.

\section{Outcomes of the clinical intervention}

An overview of the study measures is provided in Table 4. 
Table 3 Overview of the aspects of the national implementation that are evaluated and the related measurement

\begin{tabular}{|c|c|c|}
\hline Process & Definition/Measurement & Data Source \\
\hline $\begin{array}{l}\text { Spread (promotion of GLA:D Back) } \\
\text { Newsletter from professional } \\
\text { organisations } \\
\text { Information to GLA:D Knee/Hip } \\
\text { deliverers } \\
\text { Description of GLA:D Back in magazine } \\
\text { for general practitioners } \\
\text { Information on the GLA:D Back web site } \\
\text { Use of social media }\end{array}$ & $\begin{array}{l}\text { The extent to which the intended promotion } \\
\text { activities are delivered (Table 2) }\end{array}$ & Web sites, social media, e-mails \\
\hline Clinician reach & $\begin{array}{l}\text { The proportion of chiropractors and } \\
\text { physiotherapists, on a contract with the universal } \\
\text { health insurance, participating in GLA:D Back } \\
\text { courses. } \\
\text { Profile of enrolled clinicians. }\end{array}$ & Course registration \\
\hline $\begin{array}{l}\text { Penetration and adoption (extent of } \\
\text { implementation) }\end{array}$ & $\begin{array}{l}\text { Geographical penetration measured as the number } \\
\text { of municipalities with at least one GLA:D Back } \\
\text { deliverer. } \\
\text { Rate of adoption will be measured as the proportion } \\
\text { of clinics with trained clinicians offering GLA:D Back } \\
\text { (defined as having entered at least five patients in } \\
\text { the clinical registry) within } 6 \text { months of course } \\
\text { participation. } \\
\text { The number of patients starting GLA:D Back }\end{array}$ & GLA:D Back registry \\
\hline Fidelity (quality of implementation) & $\begin{array}{l}\text { The extent to which the core elements of the } \\
\text { clinical intervention are delivered }\end{array}$ & $\begin{array}{l}\text { Observations in selected clinics } \\
\text { Patient } 4 \text { month surveys }\end{array}$ \\
\hline Determinants of implementation & $\begin{array}{l}\text { The domains of knowledge, skills, beliefs about } \\
\text { capability, beliefs about consequences, innovation, } \\
\text { patients, intentions, organisation, social influences, } \\
\text { social context, and behavioural regulation are } \\
\text { captured by the Determinants of Implementation } \\
\text { Questionnaire (DIBQ) [16]. }\end{array}$ & Clinician surveys \\
\hline Patient participation & $\begin{array}{l}\text { Proportion of patients enrolled in GLA:D Back that } \\
\text { complete the program } \\
\text { Profile of enrolled patients and of completers/ } \\
\text { non-completers } \\
\text { Reasons that patients do not want to participate }\end{array}$ & $\begin{array}{l}\text { Patient surveys in the GLA:D } \\
\text { Back Registry } \\
\text { Clinician surveys }\end{array}$ \\
\hline
\end{tabular}

Knowledge and skills The Brief Illness Perception Questionnaire (B-IPQ) will be used for measuring illness beliefs [42, 43]. B-IPQ contains 9 nine items of which each covers one construct: consequences, timeline (expectations of prognosis), personal control, treatment control, identity (extent of symptoms), coherence (understanding of symptoms), emotional representation, concerns, and cause. Based on the properties of the scale observed in the pilot project, we expect to combine 'consequences', 'identity', 'concerns', and 'emotional representation' into 'Interference' (sum score 0-40), 'personal control' and 'coherence' into 'Coherence and Control' (sum score 0-20), and 'timeline' and 'treatment control' into 'Expectations' (sum score 0-20). If the internal consistency allows it, a sum score of items 1-8 will then be calculated as a measure of overall illness perceptions (0-80).

Perceived ability to perform exercises is measured by one question: 'How confident are you in performing exercises in a beneficial way?' (0-10 scale from 'not confident at all' to 'absolutely confident').
The four physical performance tests are: sit-to-stand test (number of repetitions in $30 \mathrm{~s}$ ) [44, 45]; standing forward bending ( 0 : No forward bending; 1 : pain and restricted movement; 2: no pain and restricted movement; 3: pain and unrestricted movement; 4 : no pain and unrestricted movement) [46-48]; iso-extensor endurance test (seconds in static position up till $3 \mathrm{~min}$ ) [49, 50]; trunk flexor endurance test (seconds in static position up till 2 $\min )[50,51])$. All these tests are affected in chronic LBP, and the sit-to-stand test, extensor endurance and standing forward bending have been demonstrated to be responsive to change $[52,53]$.

Beliefs and performance The B-IPQ 'Expectations' subscale measures recovery beliefs and the Fear Avoidance Beliefs Questionnaire physical activity scale $(0=$ no fear avoidance beliefs; $24=$ highest possible fear avoidance beliefs) will be used to measure fear of movement [54-56].

Self-assessed physical fitness visual analogue scales compare perceived strength, endurance, flexibility, and 


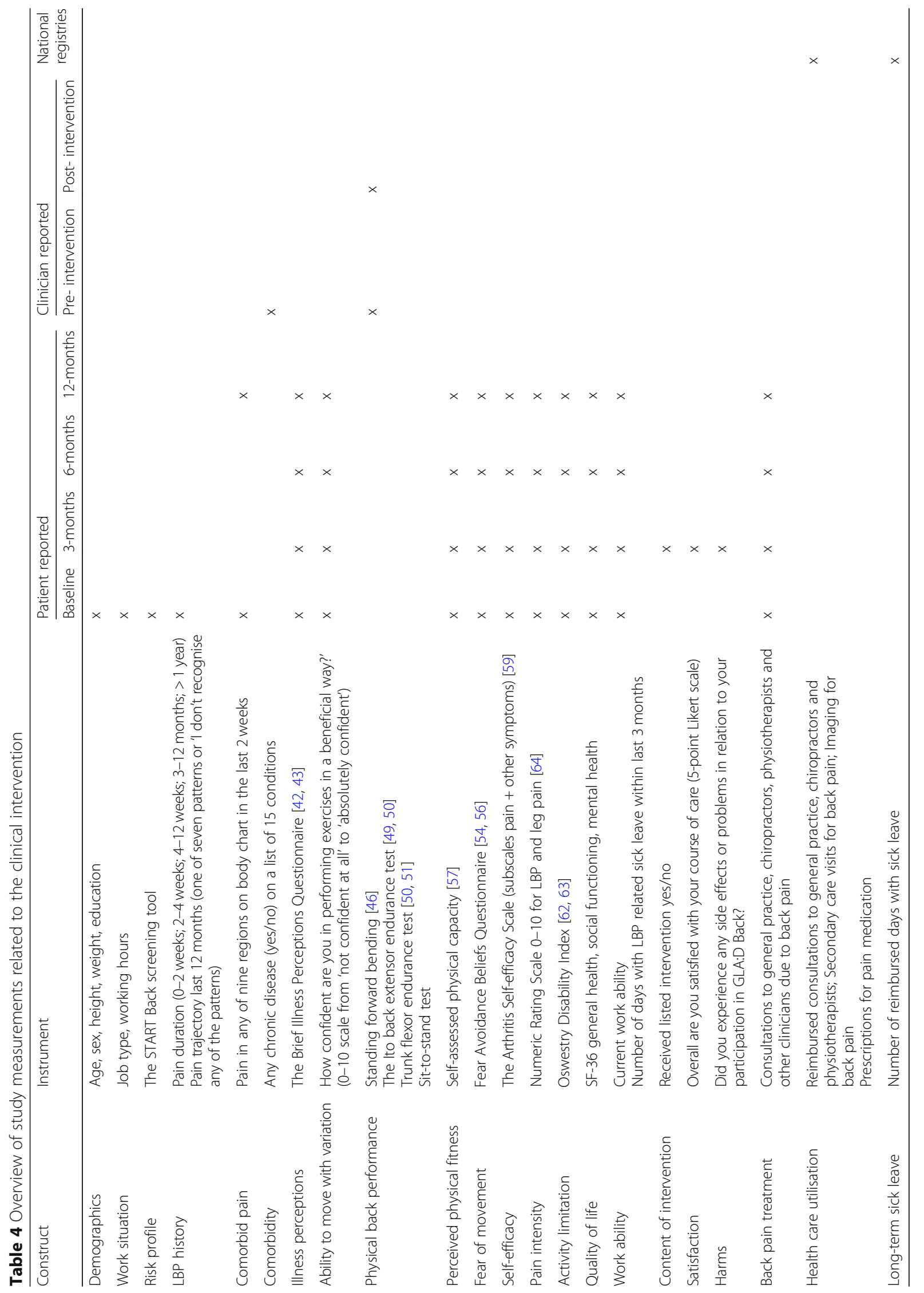


balance with that of other people of the same age and sex and is used for measuring physical fitness [57, 58]. To capture the goal of moving freely we will add one item to self-assessed physical fitness and ask to what extent the patient perceives her-/himself 'moving unhindered and naturally'.

Self-efficacy The Arthritis Self-Efficacy Scale (ASES), subscales of pain and other symptoms will be used to assess symptom self-efficacy [59]. The ASES includes five items on pain and six on other symptoms. The scale was developed for arthritis but has also undergone validation also in a mixed group of patients with chronic pain [60] and in patients with fibromyalgia [61]. The questions ask about the degree of certainty that the respondent can manage with respect to aspects around pain, sleep, fatigue and mood. Each item is scored on a $0-10$ scale $(0=$ very uncertain; $10=$ very certain). For our purposes 'arthritis' will be changed to 'back pain'.

Self-management success The Oswestry Disability Index [62, 63], work ability ('Imagine your ability to work is worth 10 points at its best. How many points will you give your current work ability?' (0-10), LBP intensity (Numeric Rating Scale 0-10 [64]), quality of life (SF-36 subdomains of general health, social functioning, mental well-being), pain interference with life (B-IPQ 'interference'), and achieved individual goal (SMART 0 $=$ Not achieved at all $-10=$ Fully achieved [40]) will be used to measure the success of self-managing pain. Because there is not one specific measure for this construct, other authors have suggested capturing a range of constructs including pain-related disability, pain intensity, quality of life, perception of social support, self-efficacy, pain acceptance, depression, anxiety, and general health as outcome measures of self-management interventions $[65,66]$.

System outcomes Health care utilisation data (number of visits to GP, chiropractor and physiotherapist, prescription of pain medication, referrals to spine imaging, and referrals to secondary care for back pain) will be extracted from the Danish National Health Service Registry [67]. In addition, patients will be asked about care-seeking due to LBP and use of pain medication for LBP. Long-term sick leave (number of days off work after 1 month of absenteeism) is available in the 'DREAM' registry from the Ministry of Employment [68].

Patient characteristics Age, sex, socio-economic status (education, job, income), LBP history (duration, recall of 1 -year trajectory, previous care), and results from the Start Back Screening Tool (low, medium and high risk of poor prognosis) [69] will be collected at baseline in addition to the outcome measures mentioned above.

\section{Outcomes of the clinician educational intervention}

An overview of the study measures is provided in Table 5.

Outcomes related to learnings The Pain Attitudes and Beliefs Scale for Physiotherapists (PABS-PT) is a self-administrated questionnaire developed to assess the strength of two possible treatment orientations of physiotherapists toward the management of back pain: predominantly biomedical orientation or predominantly behavioural orientation [70, 71]. We will use the 19-item version and added two questions based on a recent Rasch analysis of the Norwegian PABS ('If ADL activities cause more back pain, this is not dangerous'; 'Reduction of daily physical exertion is a significant factor in treating back pain') [72]. The resulting biomedical subscale will consist of 11 items (sum score 11 to 66) and the behavioural subscale of 10 items (sum score 10 to 60).

The four-item Practitioner Confidence Scale (PCS) measures clinicians' confidence in managing people with back pain [73]. Two items will be added to capture confidence about using a behavioral pain model ('I feel confident using psychological and behavioural elements in the treatment of LBP patients' and 'I feel confident working with patient with LBP not basing this on a structural diagnosis'). Each item is scored on a five-point scale from $1=$ 'strongly agree' to $5=$ 'strongly disagree', resulting in sum scores ranging from 6 to 30 .

The Determinants of Implementation Behavior Questionnaire (DIBQ) will be used to measure the domains of knowledge, skills and capabilities about the delivery of GLA:D Back [74]. The DIBQ was developed from the Theoretical Domains Framework and covers 18 domains related to implementation processes [16]. We will include 31 items from the domains of knowledge (2 items), skills (1 items), beliefs about capability (6 items), beliefs about consequences ( 4 items), innovation ( 4 items), patients (2 items), intentions ( 1 item), organisation ( 2 items), social influences (3 items), social context (1 item), behavioural regulation (3 items), and innovation strategy (2 items). Items are scored $1=$ strongly disagree to $7=$ strongly agree, with negative statements reverse-coded.

Outcomes related to clinician behaviours The delivery of a group-based patient education and exercise program will be assessed as the proportion of patients who reports participation in both of these activities. The delivery of key messages as part of the intervention will be measured as patients' recall of having heard five key messages as part of their treatment course. Three of the listed messages are key messages in the GLA:D Back approach ('Movement is healthy for the spine, 'Pain does 


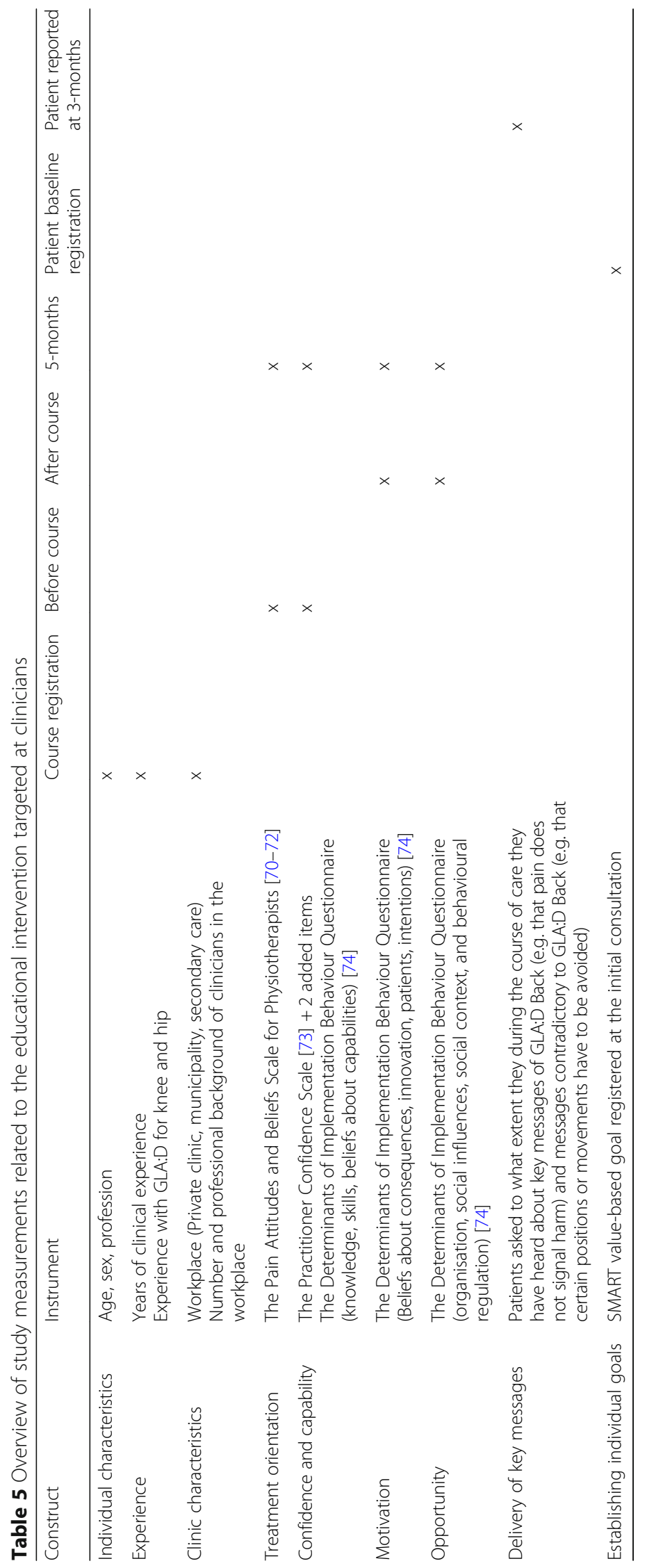


not equal harm,' 'Your brain has a memory for pain like having a bad song stuck in your head') and two are messages not in line with the intention of GLA:D Back ('I need to avoid certain positions or movements', 'In my case, pain means I should stop what I am doing'). Both measures of delivery of care are included in the patient three-month follow up. Use of individual goals will be measured as the proportion of patients for whom a goal is described in the clinical registry.

\section{Clinician and clinics characteristics}

Information will be collected to describe clinician profiles: age, sex, profession, years of clinical experience, type of employment, experience with GLA:D knee and hip, and whether or not their clinical work is conducted under a contract with public health insurance. Information will also be collected about clinics: the number of physiotherapists, chiropractors, massage therapists and other clinicians in the clinic, whether GLA:D for knee and hip is offered, and if back pain group exercises were offered before introducing GLA:D Back.

\section{Outcomes related to the national implementation}

Promotion activities Promotion of the course will be measured via the number of times GLA:D Back is mentioned in social media postings, newsletters and magazines (Table 2).

Reach, adoption and penetration Clinician reach will be quantified as the number of clinicians signing up for the GLA:D Back courses, rate of adoption as the proportion of these who enrol patients in the program, and geographical dissemination as the extent of spread across the country (Table 3 ). The profiling of clinicians will include years of clinical experience, sex, profession (physiotherapist, chiropractor), place of employment (municipality, primary care clinic, secondary care), type of employment (clinic owner, employee, self-employed in a clinic owned by another person).

Fidelity The outcome measures listed above about clinician behaviours are measures of fidelity.

Determinants of implementation The DIBQ domains that relate to national implementation are organisation, social influences, social context, and behavioural regulation.

The profile of patients enrolled Using data concerning the patient characteristics collected above, we will be able to profile patients enrolled in GLA:D Back.
Acceptability among patients Clinicians will be asked 'What proportion of invited patients would you say join GLA:D Back?' (<25\%, 25-50\%, approx. 50\%, 50-75, > $75 \%$ ), and 'What are the main reasons why patients decline participation?' (price, time point, don't want supervised training, don't want patient education, find the program too comprehensive, other reasons). If the last individual session does not occur, clinicians will report if the patient otherwise completed the intervention (Program completed without final session; Program not completed). Compliance with the program will be registered as the number of education sessions and exercise sessions patients report they attended when completing the three-months follow up.

Referrals and prescriptions Suitable outcomes from national registries and population definitions for a pre-post comparison at the national level are still to be determined and will be informed by the characteristics of the population enrolled in GLA:D Back. Available information includes reimbursed visits to general practice, physiotherapists, and chiropractors, visits and diagnostic codes from hospital visits, referrals to reimbursed imaging and prescriptions of medication.

\section{Sample size}

The study population will be the clinicians who complete GLA:D Back courses during 2018 and the patients enrolled in GLA:D Back by these clinicians during a 6-months window of inclusion commencing after a 3-month phase of familiarisation with the program after the course. Assuming that clinicians from 150 clinics will participate in the GLA:D Back course during 2018, and they enrol 1500 patients during the study period, we will have $90 \%$ power to demonstrate pre-post comparison changes at the patient level with an effect size of 0.2 while accounting for clustering within clinics and clinicians up to a variance inflation factor of 5 . At the clinician level, we will have [75]90\% power to demonstrate changes with an effect size of 0.27 .

\section{Statistical analyses and reporting}

Due to the wide scope of the study, analyses and reporting will be conducted in several dedicated subprojects. These will be organized along the main hypotheses, the main topics mentioned under "Effectiveness and process evaluations ", and the time frame of the study. A detailed analysis plan and a publication and dissemination plan will be prepared for each subproject. An initial data analysis will be performed according to the recommendations of the STRATOS (STRengthening Analytical Thinking for Observational Studies) initiative [75], informing all subprojects about the available meta data, the patient flow in the project and the distribution of 
key variables. Across all sub projects we will make use of hierarchical models to take the hierarchical structure (clinics and clinicians within clinics) into account. Latent class models will be used to detect patient and clinician profiles and structural equation models will be used to investigate the associations among latent variables. Mediation analysis will be performed according to the causal framework described by Vanderweele [76]. The overall research team takes the responsibility to prepare an additional publication summarizing the results of the different subprojects.

\section{Discussion}

This implementation-effectiveness study is designed to evaluate the process and outcomes of implementing a standardised intervention, GLA:D Back, for people with persistent or recurrent LBP. The implementation strategy targets clinicians and the clinical intervention targets people seeking care for persistent or recurrent LBP who are in need of improved self-management. In this study, we will investigate how standardised evidence-based care for LBP can become widely available, how the intervention will be delivered and to whom, what outcomes patients achieve in clinical practice, and what the effects will be at the national level. Further, we investigate potential mechanisms for effects by evaluating changes in several intermediate outcomes based on theoretical models for introducing behaviour changes and for supporting self-management of back pain.

The implementation strategy with a 2-day course for clinicians mirrors that of the GLA:D program for patients with knee and hip pain [31]. That program has achieved very large national adoption and has developed into an international model of standardised care with training of clinicians in Canada, Australia and China within only 5 years of its commencement [77, 78]. Organisations and clinicians have subsequently called for a similar model for back pain care and thus, GLA:D for knee and hip pain serves as a model for the implementation of evidence-based back pain care. A pilot study testing the feasibility of GLA:D Back showed good promise for implementation (nine test sites all enrolled patients in the GLA:D Back program within 2 months of clinicians' course participation and clinicians' and patients' perceptions were positive) (manuscript in preparation).

Despite good intentions, implementation of health care initiatives is complex, a lot of factors affect implementation and very many aspects deserve evaluation. Therefore, implementation is best understood within a theoretical framework and should be planned and evaluated within one [79]. We will use the Behavior Change Wheel, which describes interventions and policies related to change of behaviour [35]. This framework facilitates a focused evaluation and also clarifies aspects of supporting behavioural change that our implementation strategy does not include. For example, we did not involve decisions-makers in health care from the beginning of the project and are aware that the existing reimbursement structure may be an important barrier to implementation.

This study initiates a line of research with the potential to generate insight into real life effects of recommended treatments for people with persistent or recurrent LBP, and into ways to assist clinicians in delivering this care. The clinical registry will continue after the study period and will generate a cohort for future monitoring of outcomes, as well as for embedded trials for testing alterations to the education of clinicians and to the clinical intervention. Educational interventions for clinicians using a workshop format with didactic and interactive elements have been used for implementation of guidelines on back pain [80] and osteoarthritis [81], but the amount and type of training needed for clinicians to deliver a new intervention with satisfactory fidelity is unknown. Thus, the effects of a more comprehensive training of clinicians is one aspect that can be tested in a future embedded trial. Also, the investigations of intermediate outcomes may inform alterations to the clinical intervention that can then be tested for effectiveness in a nested study.

Some compromises were made in the design of this study. First, given the large evidence base for patient education and exercise, we did not aim at a further evaluation of the clinical intervention in a randomised design. Instead, we focused on the implementation of such an intervention and an investigation into how delivery of care can be optimised in clinical practice. However, also an evaluation of the educational intervention for clinicians or the overall implementation could also have been undertaken in a cluster-randomised design. Unfortunately, due to the nationwide spread of the existing GLA:D knee and hip program and the high expectations associated with its extension to low back pain patients, a randomisation at the level of clinics or regions would not have met wide acceptance, and we did not adopt that design. Pragmatically, we investigate the effect of the clinical intervention itself only by a pre-post comparison among the participating patients. We originally planned to include at least a pre-post comparison based on two cross-sectional samples drawn from each clinic prior to, and after, introducing GLA:D Back. However, as the intervention will also change the composition of the patient population approaching the clinics, it was not possible to define a relevant patient group that would have resulted in comparable pre and post populations.

Another challenge in evaluating self-management interventions is the choice of outcomes. Of course, for 
long-term outcomes at the patient and societal levels, we could use established instruments and indicators. However, our aim is also to understand the intermediate process in reaching a long-term improvement, i.e. how a better self-management is reached and how it affects the long-term outcomes. The construct of self-efficacy is relatively well-defined and related measurement tools exist. More challenging is the measuring of self-management. It is not clear what defines the ability to self-manage and a large number of different tools and constructs have been used for measuring aspects of this [66]. As part of this study, we will investigate mechanisms behind the development of self-efficacy and self-management by testing hypothesised pathways and by combining quantitative and qualitative data to improve our understanding of patients' perceptions of self-management.

In conclusion, this hybrid implementation-effectiveness study will evaluate efforts to implement a program aimed at promoting self-management of persistent and recurrent back pain in people presenting in Danish primary care and demonstrate what the actual target group is for this type of care and the outcomes achieved. This will help to develop strategies for implementing evidence-based care for back pain and potentially other musculoskeletal pain conditions.

\section{Organisation}

The study is conducted by University of Southern Denmark, Department of Sports Science and Clinical Biomechanics. An advisory board is informed about study plans and progress and provides input but has no authority over project activities. University of Southern Denmark holds the GLA:D ${ }^{\circ}$ trademark.

\section{Additional files}

Additional file 1: Plan for the two-day course. (DOCX $20 \mathrm{~kb}$ )

Additional file 2: English translation of patient consent. (PDF 107 kb)

\section{Abbreviations}

ASES: Arthritis Self-Efficacy Scale; BCW: Behaviour Change Wheel; B-IPQ: Brief IIIness Perceptions Questionnaire; DIBQ: Determinants of Implementation Behaviour Questionnaire; DPA: Danish Data Protection Agency; GLA:D: Good Life with osteoArthritis in Denmark (only the acronym is used in GLA:D Back); GP: General Practitioner; LBP: Low back pain; OPEN: Odense Patient data Explorative Network; PABS: Pain Attitudes and Beliefs Scale; PCS: Practitioner Confidence Scale; RCT: Randomised Controlled Trial

\section{Acknowledgements}

We would like to acknowledge Professor Ewa Roos and Associate Professor Søren Thorgaard Skou for sharing the GLA:D model and their experiences with implementing this; Associate Professor Lotte O'Neill from the SDU Centre for Teaching and Learning for her input to defining learning goals and evaluating the clinician course; the Odense Patient data Explorative Network for access to REDCap for advice on the data base structure and support with the electronic data collection; Suzanne Capell for proof reading. Finally, the GLA:D Back advisory group is acknowledged for their input to the project. The advisory group members are:
Professor Ewa M Roos, Centre for Muscle and Joint Health, SDU, DenmarkProfessor Birgitta Öberg, Department of Medical and Health Sciences, Linköping University, SwedenDirector and Research Leader Henrik Wulff Christensen, Nordic Institute of Chiropractic and Clinical Biomechanics, Odense, Denmark.

Associate Professor Christian von Plessen, Centre for Quality, Region of Southern Denmark, Denmark.

Professor Jens Søndergaard, Research Unit of General Practice, SDU, Denmark. Associate Professor Søren T Skou, Centre for Muscle and Joint Health, SDU, Denmark. Professor Bart Koes, Department of General Practice, Erasmus MC, Rotterdam, The Netherlands.

Professor Chris Maher, Sydney School of Public Health, The University of Sydney, Australia.

Professor Berit Schiøttz-Christensen, The Spine Centre of Southern Denmark, Denmark.

Associate Professor Tonny Andersen, Department of Psychology, SDU, Denmark. Business Developer Lars Stig Møller, Business Alliance, Research \& Innovation Organisation, SDU, Denmark.

Professor Per Nilsen, Department of Medical and Health Sciences, Linköping University, Sweden.

\section{Funding}

No funding was obtained for the work. The development of the study was financed by University of Southern Denmark through salaries to the research team, and profit from clinician payed courses will be used within the project. Additional funding of subprojects is applied for.

\section{Availability of data and materials}

Not applicable

\section{Authors' contributions}

$A K, I R, P K, W V$ and $J H$ have all been involved in designing the study; LM led the design of the external process evaluation. All provided input to the manuscript and all authors have read and approved the final manuscript. AK drafted the manuscript.

\section{Ethics approval and consent to participate}

The data collection has obtained authorisation from the Danish Data Protection Agency (DPA) as part of the University of Southern Denmark's institutional authorisation (DPA no. 2015-57-0008 SDU no. 17/30591). The Regional Committees on Health Research Ethics for Southern Denmark decided that the study did not need ethical approval (file number S-20172000-93). When registered by the clinician, the patient receives an email with link to a patient reported survey. Written information about the study, data protection and participants' rights are in the survey with a request to confirm consent for using data for research purposes (Additional file 2). The treatments offered to patients are not influenced by study participation. Clinicians agree to the requirements for GLA:D Back certification and consent that data are used for investigating reach and adoption when signing up for the course. Consent that data are

used for research purposes in general is provided at the four-months follow-up.

Consent for publication

The manuscript does not include any individual person's data.

\section{Competing interests}

AK's position at the University of Southern Denmark is financially supported by the Foundation for Chiropractic Research and Postgraduate Education, and IR's position is supported by income from the GLA:D Back clinician courses. GLA:D ${ }^{\circledR}$ is a non-profit initiative hosted at the University of Southern Denmark and the GLA:D ${ }^{\oplus}$ trademark is property of the University of Southern Denmark. The GLA:D initiative is developed in close collaboration with the SDU Research \& Innovation Organisation, including legal reviews. The researchers do not have any personal financial benefits from working with the project. Since there is a substantial overlap between the developers of the intervention and the investigators of this study, we will ask members of the advisory board who are neither involved in development of the intervention nor in the study itself to take on the role of monitoring data and safety. The study team will continuously report interim results to the advisory board and discuss the need for major changes in the conduct of the study. The members 
of the advisory board will be given access to the data of the study on request. AK, PK, and JH are editorial board members for BMC Musculoskeletal Disorders.

\section{Publisher's Note}

Springer Nature remains neutral with regard to jurisdictional claims in published maps and institutional affiliations.

\section{Author details}

${ }^{1}$ The Nordic Institute of Chiropractic and Clinical Biomechanics, Campusvej 55, 5230 Odense M, Denmark. ²Department of Sports Science and Clinical Biomechanics, University of Southern Denmark, Odense, Denmark. ${ }^{3}$ Department of Applied Health Science, University College Lillebaelt, Odense, Denmark. ${ }^{4}$ Department of Orthopaedics and Traumatology, University Hospital Basel, Basel, Switzerland. ${ }^{5}$ Centre for Quality, Department of Regional Health Research, University of Southern Denmark, Middelfart, Denmark.

\section{Received: 10 June 2018 Accepted: 30 January 2019}

Published online: 18 February 2019

\section{References}

1. Collaborators GDallaP. Global, regional, and national incidence, prevalence, and years lived with disability for 328 diseases and injuries for 195 countries, 1990-2016: a systematic analysis for the global burden of disease study 2016. Lancet. 2017;390:1211-59. https://doi.org/10.1016/s0140-6736(17)32154-2.

2. Hartvigsen J, Hancock MJ, Kongsted A, Louw Q, Ferreira ML, Genevay S, et al. What low back pain is and why we need to pay attention. Lancet. 2018 https://doi.org/10.1016/S0140-6736(18)30480-X

3. Maniadakis N, Gray A. The economic burden of back pain in the UK. Pain. 2000;84:95-103 PM:10601677.

4. Wong JJ, Cote P, Sutton DA, Randhawa $\mathrm{K}, \mathrm{Yu} \mathrm{H}$, Varatharajan S, et al. Clinical practice guidelines for the noninvasive management of low back pain: a systematic review by the Ontario protocol for traffic injury management (OPTIMa) collaboration. Eur J Pain. 2017;21:201-16. https://doi.org/10.1002/ ejp.931.

5. Stochkendahl MJ, Kjaer P, Hartvigsen J, Kongsted A, Aaboe J, Andersen M, et al. National Clinical Guidelines for non-surgical treatment of patients with recent onset low back pain or lumbar radiculopathy. Eur Spine J. 2018;27: 60-75. https://doi.org/10.1007/s00586-017-5099-2.

6. National Guideline C. National Institute for Health and Care Excellence: Clinical Guidelines. In: Low Back Pain and Sciatica in Over 16s: Assessment and Management. London: National Institute for Health and Care Excellence (UK) Copyright (c) NICE; 2016

7. Dixon-Woods M, McNicol S, Martin G. Ten challenges in improving quality in healthcare: lessons from the Health Foundation's programme evaluations and relevant literature. BMJ Qual Saf. 2012;21:876-84. https://doi.org/10. 1136/bmjqs-2011-000760.

8. Lenfant C. Clinical research to clinical practice - lost in translation? N Engl J Med. 2003;349:868-74. https://doi.org/10.1056/NEJMsa035507.

9. Fischer F, Lange K, Klose K, Greiner W, Kraemer A. Barriers and Strategies in Guideline Implementation-A Scoping Review. Healthcare (Basel). 2016;4. https://doi.org/10.3390/healthcare4030036.

10. Liang L, Abi Safi J, Gagliardi AR. Number and type of guideline implementation tools varies by guideline, clinical condition, country of origin, and type of developer organization: content analysis of guidelines. Implement Sci. 2017;12: 136. https://doi.org/10.1186/s13012-017-0668-7.

11. Suman A, Dikkers MF, Schaafsma FG, van Tulder MW, Anema JR. Effectiveness of multifaceted implementation strategies for the implementation of back and neck pain guidelines in health care: a systematic review. Implement Sci. 2016; 11:126. https://doi.org/10.1186/s13012-016-0482-7.

12. Mesner SA, Foster NE, French SD. Implementation interventions to improve the management of non-specific low back pain: a systematic review. BMC Musculoskelet Disord. 2016:17:258. https://doi.org/10.1186/s12891-016-1110-z

13. Slade SC, Kent P, Patel S, Bucknall T, Buchbinder R. Barriers to primary care clinician adherence to clinical guidelines for the Management of low Back Pain: a systematic review and Metasynthesis of qualitative studies. Clin J Pain. 2016;32:800-16. https://doi.org/10.1097/ajp.0000000000000324.

14. Foster NE, Anema JR, Cherkin D, Chou R, Cohen SP, Gross DP, et al. Prevention and treatment of low back pain: evidence, challenges, and promising directions. Lancet. 2018. https://doi.org/10.1016/S01406736(18)30489-6.
15. Buchbinder $R$, van Tulder M, Oberg B, Costa LM, Woolf A, Schoene M, et al. Low back pain: a call for action. Lancet. 2018. https://doi.org/10.1016/S01406736(18)30488-4.

16. Cane J, O'Connor D, Michie S. Validation of the theoretical domains framework for use in behaviour change and implementation research. Implement Sci. 2012;7:37. https://doi.org/10.1186/1748-5908-7-37.

17. Lamb SE, Hansen Z, Lall R, Castelnuovo E, Withers EJ, Nichols V, et al. Group cognitive behavioural treatment for low-back pain in primary care: a randomised controlled trial and cost-effectiveness analysis. Lancet. 2010;375: 916-23. https://doi.org/10.1016/s0140-6736(09)62164-4.

18. Hill JC, Whitehurst DG, Lewis M, Bryan S, Dunn KM, Foster NE, et al. Comparison of stratified primary care management for low Back pain with current best practice (STarT Back): a randomised controlled trial. Lancet. 2011;378:1560-71. https://doi.org/10.1016/S0140-6736(11)60937-9.

19. Foster NE, Mullis R, Hill JC, Lewis M, Whitehurst DG, Doyle C, et al. Effect of stratified care for low Back pain in family practice (IMPaCT Back): a prospective population-based sequential comparison. Ann Fam Med. 2014; 12:102-11. https://doi.org/10.1370/afm.1625.

20. Lee H, Hubscher M, Moseley GL, Kamper SJ, Traeger AC, Mansell G, et al. How does pain lead to disability? A systematic review and meta-analysis of mediation studies in people with back and neck pain. Pain. 2015;156:98897. https://doi.org/10.1097/j.pain.0000000000000146.

21. Hall AM, Kamper SJ, Emsley R, Maher CG. Does pain-catastrophising mediate the effect of tai chi on treatment outcomes for people with low back pain? Complement Ther Med. 2016;25:61-6. https://doi.org/10.1016/j. ctim.2015.12.013.

22. Smeets RJ, Vlaeyen JW, Kester AD, Knottnerus JA. Reduction of pain catastrophizing mediates the outcome of both physical and cognitivebehavioral treatment in chronic low back pain. J Pain. 2006;7:261-71. https://doi.org/10.1016/j.jpain.2005.10.011.

23. Spinhoven P, Ter Kuile M, Kole-Snijders AM, Hutten Mansfeld M, Den Ouden DJ, Vlaeyen JW. Catastrophizing and internal pain control as mediators of outcome in the multidisciplinary treatment of chronic low back pain. Eur J Pain. 2004;8:211-9. https://doi.org/10.1016/j.ejpain.2003.08.003.

24. O'Keeffe M, Cullinane P, Hurley J, Leahy I, Bunzli S, O'Sullivan PB, et al. What influences patient-therapist interactions in musculoskeletal physical therapy? Qualitative systematic review and Meta-synthesis. Phys Ther. 2016;96:609-22. https://doi.org/10.2522/ptj.20150240.

25. Fuentes J, Armijo-Olivo S, Funabashi M, Miciak M, Dick B, Warren S, et al. Enhanced therapeutic alliance modulates pain intensity and muscle pain sensitivity in patients with chronic low back pain: an experimental controlled study. Phys Ther. 2014;94:477-89. https://doi.org/10.2522/ptj.20130118.

26. Testa M, Rossettini G. Enhance placebo, avoid nocebo: how contextual factors affect physiotherapy outcomes. Man Ther. 2016;24:65-74. https://doi. org/10.1016/j.math.2016.04.006

27. Linton SJ, Flink IK, Vlaeyen JWS. Understanding the etiology of chronic pain from a psychological perspective. Phys Ther. 2018;98:315-24. https://doi.org/ 10.1093/ptj/pzy027.

28. Glasgow RE, Lichtenstein E, Marcus AC. Why don't we see more translation of health promotion research to practice? Rethinking the efficacy-toeffectiveness transition. Am J Public Health. 2003:93:1261-7.

29. Curran GM, Bauer M, Mittman B, Pyne JM, Stetler C. Effectiveness-implementation hybrid designs: combining elements of clinical effectiveness and implementation research to enhance public health impact. Med Care. 2012;50:217-26. https:/doi. org/10.1097/MLR.0b013e3182408812.

30. Kjaer P, Kongsted A, Ris I, Abbott A, Rasmussen CDN, Roos EM, et al. GLA:D ${ }^{\circledR}$ Back group-based patient education integrated with exercises to support self-management of back pain - development, theories and scientific evidence. BMC Musculoskelet Disord. 2018;19:418. https://doi.org/10.1186/ s12891-018-2334-X.

31. Skou ST, Roos EM. Good life with osteoArthritis in Denmark (GLA:D): evidence-based education and supervised neuromuscular exercise delivered by certified physiotherapists nationwide. BMC Musculoskelet Disord. 2017;18:72. https://doi.org/10.1186/s12891-017-1439-y.

32. Kongsted A, Hartvigsen J, Boyle E, Ris I, Kjaer P, Thomassen L, et al. GLA:D Back: Group-based patient education and exercises to support selfmanagement of persistent back pain. Feasibility of implementation by a clinician course. Submitted for publication. 2018.

33. Pinnock H, Barwick M, Carpenter CR, Eldridge S, Grandes G, Griffiths CJ, et al. Standards for reporting implementation studies (StaRI) statement. BMJ. 2017;356:i6795. https://doi.org/10.1136/bmj.i6795. 
34. Phillips AC, Lewis LK, McEvoy MP, Galipeau J, Glasziou P, Moher D, et al. Development and validation of the guideline for reporting evidence-based practice educational interventions and teaching (GREET). BMC Med Educ. 2016;16:237. https://doi.org/10.1186/s12909-016-0759-1.

35. Michie S, van Stralen MM, West R. The behaviour change wheel: a new method for characterising and designing behaviour change interventions. Implement Sci. 2011;6:42. https://doi.org/10.1186/1748-5908-6-42.

36. Organisation for Economic C-o, Development S. Primary Care in Denmark. Paris: Lanham Organization for Economic Cooperation \& Development, Rowman \& Littlefield Publishers, Incorporated Distributor; 2017. Available from: https://www.oecd.org/els/primary-care-in-denmark-9789264269453-en.htm.

37. The Danish Health Data Authority. [Ydere indenfor praksissektoren] esundhed. dk2018 [cited 2018 5-5-2018]. Available from: http://esundhed.dk/ sundhedsaktivitet/arbejdsmarked/ydere/Sider/Ydere01.aspx.

38. Nielsen OL, Kongsted A, Christensen HW. The chiropractic profession in Denmark 2010-2014: a descriptive report. Chiropr Man Therap. 2015;23:27. https://doi.org/10.1186/s12998-015-0072-9.

39. Turk DC. Cognitive-behavioral approach to the treatment of chronic pain patients. Reg Anesth Pain Med. 2003;28:573-9.

40. Bovend'Eerdt TJ, Botell RE, Wade DT. Writing SMART rehabilitation goals and achieving goal attainment scaling: a practical guide. Clin Rehabil. 2009;23: 352-61. https://doi.org/10.1177/0269215508101741.

41. OPEN. Odense Patient data Explorative Network Available from: https:// www.sdu.dk/en/Om_SDU/Institutter_centre/Klinisk_institut/Forskning/ Forskningsenheder/open.aspx.

42. Leysen M, Nijs J, Meeus M, Paul van Wilgen C, Struyf F, Vermandel A, et al. Clinimetric properties of illness perception questionnaire revised (IPQ-R) and brief illness perception questionnaire (brief IPQ) in patients with musculoskeletal disorders: a systematic review. Man Ther. 2015;20:10-7. https://doi.org/10.1016/j.math.2014.05.001.

43. Broadbent E, Wilkes C, Koschwanez H, Weinman J, Norton S, Petrie KJ. A systematic review and meta-analysis of the brief illness perception questionnaire. Psychol Health. 2015;30:1361-85. https://doi.org/10.1080/ 08870446.2015 .1070851$.

44. Jones CJ, Rikli RE, Beam WC. A 30-s chair-stand test as a measure of lower body strength in community-residing older adults. Res Q Exerc Sport. 1999; 70:113-9. https://doi.org/10.1080/02701367.1999.10608028.

45. Denteneer L, Van Daele U, Truijen S, De Hertogh W, Meirte J, Stassijns G. Reliability of physical functioning tests in patients with low back pain: a systematic review. Spine J. 2018;18:190-207. https://doi.org/10.1016/j.spinee. 2017.08.257.

46. Gauvin MG, Riddle DL, Rothstein JM. Reliability of clinical measurements of forward bending using the modified fingertip-to-floor method. Phys Ther. 1990;70:443-7.

47. Matyas TA, Bach TM. The reliability of selected techniques in clinical arthrometrics. Aust J Physiother. 1985;31:175-99. https://doi.org/10.1016/ S0004-9514(14)60633-4.

48. Newton M, Waddell G. Reliability and Validity of Clinical Measurement of the Lumbar Spine in Patients with Chronic Low Back Pain. Physiotherapy. 1991;77:796-800. doi: https://doi.org/10.1016/S0031-9406(10)61906-2.

49. Ito T, Shirado O, Suzuki H, Takahashi M, Kaneda K, Strax TE. Lumbar trunk muscle endurance testing: an inexpensive alternative to a machine for evaluation. Arch Phys Med Rehabil. 1996;77:75-9.

50. Arab AM, Salavati M, Ebrahimi I, Ebrahim MM. Sensitivity, specificity and predictive value of the clinical trunk muscle endurance tests in low back pain. Clin Rehabil. 2007;21:640-7. https://doi.org/10.1177/0269215507076353.

51. Moreland J, Finch E, Stratford P, Balsor B, Gill C. Interrater reliability of six tests of trunk muscle function and endurance. J Orthop Sports Phys Ther. 1997:26:200-8. https://doi.org/10.2519/jospt.1997.26.4.200.

52. Strand LI, Anderson B, Lygren H, Skouen JS, Ostelo R, Magnussen LH. Responsiveness to change of 10 physical tests used for patients with back pain. Phys Ther. 2011;91:404-15. https://doi.org/10.2522/pti.20100016.

53. Andersson El, Lin CC, Smeets RJ. Performance tests in people with chronic low back pain: responsiveness and minimal clinically important change. Spine (Phila Pa 1976). 2010;35:E1559-63. https://doi.org/10.1097/BRS Ob013e3181cea12e.

54. Waddell G, Newton M, Henderson I, Somerville D, Main CJ. A Fear-Avoidance Beliefs Questionnaire (FABQ) and the role of fear- avoidance beliefs in chronic low back pain and disability. Pain. 1993;52:157-68 PM:0008455963.

55. Woby SR, Watson PJ, Roach NK, Urmston M. Are changes in fear-avoidance beliefs, catastrophizing, and appraisals of control, predictive of changes in chronic low back pain and disability? Eur J Pain. 2004;8:201-10 PM: 15109970.

56. Grotle M, Brox Jl, Vollestad NK. Reliability, validity and responsiveness of the fear-avoidance beliefs questionnaire: methodological aspects of the Norwegian version. J Rehabil Med. 2006;38:346-53. https://doi.org/10. 1080/16501970600722403.

57. Stroyer J, Essendrop M, Jensen LD, Warming S, Avlund K, Schibye B. Validity and reliability of self-assessed physical fitness using visual analogue scales. Percept Mot Skills. 2007;104:519-33. https://doi.org/10.2466/pms.104.2.519-533.

58. Rasmussen CD, Jorgensen MB, Clausen T, Andersen LL, Stroyer J, Holtermann A. Does self-assessed physical capacity predict development of low back pain among health care workers? A 2-year follow-up study. Spine (Phila Pa 1976). 2013;38:272-6. https://doi.org/10.1097/BRS.0b013e31826981f3.

59. Primdahl J, Wagner L, Horslev-Petersen K. Self-efficacy in rheumatoid arthritis: translation and test of validity, reliability and sensitivity of the Danish version of the rheumatoid arthritis self-efficacy questionnaire (RASE). Musculoskeletal Care. 2010;8:123-35. https://doi.org/10.1002/msc.172.

60. Lomi C, Nordholm LA. Validation of a Swedish version of the arthritis selfefficacy scale. Scand J Rheumatol. 1992;21:231-7.

61. Lomi C, Burckhardt C, Nordholm L, Bjelle A, Ekdahl C. Evaluation of a Swedish version of the arthritis self-efficacy scale in people with fibromyalgia. Scand J Rheumatol. 1995;24:282-7.

62. Lauridsen HH, Hartvigsen J, Manniche C, Korsholm L, Grunnet-Nilsson N. Danish version of the Oswestry disability index for patients with low back pain. Part 2: sensitivity, specificity and clinically significant improvement in two low back pain populations. Eur Spine J. 2006;15:1717-28. https://doi. org/10.1007/s00586-006-0128-6.

63. Lauridsen HH, Hartvigsen J, Manniche C, Korsholm L, Grunnet-Nilsson N. Danish version of the Oswestry disability index for patients with low back pain. Part 1: cross-cultural adaptation, reliability and validity in two different populations. Eur Spine J. 2006;15:1705-16. https://doi.org/10.1007/s00586006-0117-9.

64. Strong J, Ashton R, Chant D. Pain intensity measurement in chronic low back pain. Clin J Pain. 1991;7:209-18 PM:1839716.

65. Taylor SJC, Carnes D, Homer K, Pincus T, Kahan BC, Hounsome N, et al. Improving the self-management of chronic pain: COping with persistent pain, effectiveness research in self-management (COPERS). Southampton: Programme Grants for Applied Research; 2016.

66. Boger E, Ellis J, Latter S, Foster C, Kennedy A, Jones F, et al. Self-management and self-management support outcomes: a systematic review and mixed research synthesis of stakeholder views. PLoS One. 2015;10:e0130990. https:// doi.org/10.1371/journal.pone.0130990.

67. Andersen JS, Olivarius Nde F, Krasnik A. The Danish National Health Service Register. Scand J Public Health. 2011;39:34-7. https://doi.org/10.1177/ 1403494810394718.

68. Stapelfeldt CM, Jensen C, Andersen NT, Fleten N, Nielsen CV. Validation of sick leave measures: self-reported sick leave and sickness benefit data from a Danish national register compared to multiple workplace-registered sick leave spells in a Danish municipality. BMC Public Health. 2012;12:661. https://doi.org/10.1186/1471-2458-12-661.

69. Hill JC, Dunn KM, Lewis M, Mullis R, Main CJ, Foster NE, et al. A primary care back pain screening tool: identifying patient subgroups for initial treatment. Arthritis Rheum. 2008:59:632-41 PM:18438893.

70. Ostelo RW, Stomp-van den Berg SG, Vlaeyen JW, Wolters PM, de Vet HC. Health care provider's attitudes and beliefs towards chronic low back pain: the development of a questionnaire. Man Ther. 2003;8:214-22.

71. Houben RM, Ostelo RW, Vlaeyen JW, Wolters PM, Peters M, Stomp-van den Berg SG. Health care providers' orientations towards common low back pain predict perceived harmfulness of physical activities and recommendations regarding return to normal activity. Eur J Pain. 2005;9:173-83. https://doi.org/10 1016/j.ejpain.2004.05.002.

72. Eland ND, Kvale A, Ostelo RW, Strand LI. The pain attitudes and beliefs scale for physiotherapists: dimensionality and internal consistency of the Norwegian version. Physiother Res Int. 2016. https://doi.org/10.1002/pri.1670.

73. Bush T, Cherkin D, Barlow W. The impact of physician attitudes on patient satisfaction with care for low back pain. Arch Fam Med. 1993;2:301-5.

74. Huijg JM, Gebhardt WA, Dusseldorp E, Verheijden MW, van der Zouwe N, Middelkoop BJ, et al. Measuring determinants of implementation behavior: psychometric properties of a questionnaire based on the theoretical domains framework. Implement Sci. 2014;9:33. https://doi.org/10.1186/17485908-9-33. 
75. Huebner A, le Cessie S, Schmidt CO, Vach W. A Contemporary Conceptual Framework for Initial Data Analysis. Obs Stud. 2018;4:171-92.

76. Vanderweele TJ. Explanation in Causal Inference: Methods for Mediation and Interaction. New York: Oxford University Press; 2016

77. Davis AM, Kennedy D, Wong R, Robarts S, Skou ST, McGlasson R, et al. Crosscultural adaptation and implementation of good life with osteoarthritis in Denmark (GLA:D): group education and exercise for hip and knee osteoarthritis is feasible in Canada. Osteoarthritis Cartilage. 2018;26:211-9. https://doi.org/10. 1016/j.joca.2017.11.005.

78. Roos EM, Barton CJ, Davis AM, McGlasson R, Kemp JL, Crossley KM, et al. GLA:D to have a high-value option for patients with knee and hip arthritis across four continents: good life with osteoArthritis from Denmark. Br J Sports Med. 2018. https://doi.org/10.1136/bjsports-2017-098904.

79. Eccles M, Grimshaw J, Walker A, Johnston M, Pitts N. Changing the behavior of healthcare professionals: the use of theory in promoting the uptake of research findings. J Clin Epidemiol. 2005;58:107-12. https://doi.org/10.1016/j. jclinepi.2004.09.002.

80. French SD, McKenzie JE, O'Connor DA, Grimshaw JM, Mortimer D, Francis JJ, et al. Evaluation of a theory-informed implementation intervention for the management of acute low back pain in general medical practice: the IMPLEMENT cluster randomised trial. PLoS One. 2013;8:e65471. https:// doi.org/10.1371/journal.pone.0065471.

81. Porcheret M, Main C, Croft P, McKinley R, Hassell A, Dziedzic K. Development of a behaviour change intervention: a case study on the practical application of theory. Implement Sci. 2014;9:42. https://doi.org/10.1186/1748-5908-9-42.

Ready to submit your research? Choose BMC and benefit from:

- fast, convenient online submission

- thorough peer review by experienced researchers in your field

- rapid publication on acceptance

- support for research data, including large and complex data types

- gold Open Access which fosters wider collaboration and increased citations

- maximum visibility for your research: over $100 \mathrm{M}$ website views per year

At $\mathrm{BMC}$, research is always in progress.

Learn more biomedcentral.com/submissions 